\title{
Cooperation in Product Development and Process R\&D Between Competitors
}

\section{Citation}

Bourreau, Marc, and Pinar Dogan. 2010. Cooperation in Product Development and Process R\&D Between Competitors. International Journal of Industrial Organization 28(2): 176-190.

\section{Published Version}

http://dx.doi.org/10.1016/j.ijindorg.2009.07.010

\section{Permanent link}

http://nrs.harvard.edu/urn-3:HUL.InstRepos:4863170

\section{Terms of Use}

This article was downloaded from Harvard University's DASH repository, and is made available under the terms and conditions applicable to Open Access Policy Articles, as set forth at http:// nrs.harvard.edu/urn-3:HUL.InstRepos:dash.current.terms-of-use\#OAP

\section{Share Your Story}

The Harvard community has made this article openly available.

Please share how this access benefits you. Submit a story.

Accessibility 


\title{
Cooperation in Product Development and Process R\&D
}

\section{Between Competitors*}

\author{
Marc Bourreau ${ }^{\dagger}$ and Pınar Doğan
}

July 29, 2009

\begin{abstract}
In this paper, we first provide a simple framework for cooperation in product development between competitors. We put forward the tradeoff between the benefits obtained through development cost sharing and the cost of intensified competition due to reduced product differentiation, which implies that no cooperation can be an equilibrium outcome. We allow for firms to cooperate partially, i.e., to develop some product components jointly, but not necessarily all components. This enables us to study the factors that may have an effect on the degree of cooperation in product development, both in the presence and in the absence of process $R \& D$. We also analyze the interaction between cooperation decisions on product development and process R\&D. By considering a direct link between the two, we show that the degree of cooperation in product development may adversely affect the intensity of cooperation in process R\&D.

Keywords: Cooperation, Product Development, Process R\&D.

JEL Codes: L1, O3.
\end{abstract}

\footnotetext{
${ }^{*}$ We appreciate the comments of the participants at the 2007 EARIE Conference (Valencia, Spain) and the 2007 Journées de Microéconomie Appliquée (Fribourg, Switzerland). We are grateful to two anonymous referees for very useful remarks and suggestions. We also thank Katie Naeve for her editorial assistance.

${ }^{\dagger}$ Telecom ParisTech and CREST-LEI, Paris, FRANCE. E-mail: marc.bourreau@telecom-paristech.fr

${ }^{\ddagger}$ Harvard Kennedy School of Government, Harvard University. Address: 79 JFK Street, Cambridge, MA, 02138. Phone: 617496 6757, fax: 617496 5747. E-mail: pinar_dogan@ksg.harvard.edu
} 


\section{Introduction}

Many products are made of distinct product components that, on their own, have no value to end consumers. In the automotive industry, for instance, a number of product components (e.g., engine, break system, suspension system, etc.) are used to produce a single vehicle. Usually, one distinct product component can be used to produce a variety of products, provided that the relevant interfaces in different varieties are fairly standardized. This is why different firms (that may or may not be competitors) often agree to develop some product components through cooperative R\&D. For example, in September 2005, the BMW Group, DaimlerChrysler AG, and General Motors Corporation signed an agreement to form an alliance for the joint development of a two-mode hybrid drive system for engines that would allow the vehicles to switch to a different driving mode depending on the driving conditions (i.e., in city driving or highway driving). The two-mode hybrid system is now used in different vehicles of all three participants. ${ }^{1}$ While firms cooperate on the development of a particular product component, each one of them pursues its independent $R \& D$ for other product components that are necessary for the creation of a functional end-product.

This real-world example illustrates the first important point we would like to emphasize in this paper; firms often cooperate only partially -if at all, and besides the well acknowledged reasons like high transaction costs, this can also be due to the impact of cooperation on product competition. The co-opetitors' (the firms that cooperate in R\&D but compete in product markets) explicit decision on how much to cooperate may also involve an implicit decision on how much to compete. This is because even if firms may prefer a higher degree of differentiation (softer product competition) at the outset, they may have limited ability to differentiate their products when they engage in joint product development for too many product components. ${ }^{2}$ This, in turn, may imply that joint product development, along with its benefits, may involve a cost in terms of intensified product competition, which may be significant in markets where product differentiation matters to consumers. With very few exceptions, notably Vilasuso and Frascatore (2000), Lambertini et al (2002, 2003), and Ghosh and Morita (2006, 2008), the existing literature does not consider any

\footnotetext{
${ }^{1}$ For example, in the 2008 model year GM introduced the Chevrolet Tahoe, the GMC Yukon, and the Cadillac Escalade SUVs, while DaimlerChrysler launched a Dodge Durango SUV with the two-mode hybrid system.

${ }^{2}$ Firms seem to be aware of this trade-off, and often make public statements to underline how their end-products will be "different" despite the cooperative agreement. For example, after mentioning the benefits of the alliance between BMW Group, DaimlerChrysler AG, and General Motors Corporation, a member of the Board of Management for Development and Procurement at BMW AG, Prof. Burkhard Göschel, added that "Because the technologies will be adapted to the individual vehicle models, the participating brands will retain their distinctive characters" (News and Issues, Sept. 9, 2005, available at http://www.gm.com).
} 
economic cost of cooperation; ${ }^{3}$ it concludes that cooperation is, at least in a weak sense, desirable for firms since they can always replicate the non-cooperative equilibrium. Furthermore, product innovations, by and large, are treated as horizontal improvements in products, ${ }^{4}$ i.e., investments in product differentiation. In accord with this view, cooperation in product innovations is usually modeled as firms jointly setting the degree of substitution between the products so as to maximize their joint profits. ${ }^{5}$ We find modeling of product development cooperation as firms jointly setting the degree of substitutability between their products or sharing the cost of product differentiation not satisfactory.

We also account for the fact that in a variety of industries, potential competitors cooperate both in product and process innovations. In the majority of the $R \& D$ joint ventures that are formed in the automotive industry, for instance, partners cooperate not only on the development of certain product components but also on research to discover more cost-efficient ways to produce those components. For example, BMW, DaimlerChrysler, and General Motors Co. can also cooperate to attain vertical -either cost or quality- improvements on their hybrid system. ${ }^{6}$ However, it is very unlikely that they would jointly carry such process R\&D on distinct product components they have developed independently (such as the break systems). Instead, each firm conducts in-house process $\mathrm{R} \& \mathrm{D}$ on these product components, thus suggesting a direct link between product and process $\mathrm{R} \& \mathrm{D}$ decisions -a link that has been overlooked in the literature and on which this paper aims its focus. With very few exceptions, the literature on $R \& D$ cooperation accounts for a single type of $R \& D$ activity-product or process. ${ }^{7}$ The papers that consider both types of R\&D activities, notably Lin

\footnotetext{
${ }^{3}$ Vilasuso and Frascatore (2000) consider an exogenous fixed cost of forming a Research Joint Venture, which can be attributed to its management or auditing. In Lambertini et al. (2002, 2003) when firms cooperate in product innovation they develop a single product, whereas they produce differentiated products when they do not cooperate. Therefore, cooperative R\&D comes with a cost; it leads to fierce competition post-innovation unless firms collude at the competition stage. Ghosh and Morita $(2006,2008)$ also consider a similar cost, but when cooperation takes the form of platform sharing.

${ }^{4}$ See Eswaran and Gallini (1996) for a brief discussion on horizontal versus vertical innovations.

${ }^{5}$ See, for example, Lin and Saggi (2002). The authors assume an "initial" level of product substitutability between the products, and product innovation involves investment in differentiation. In such a setting, cooperation in product R\&D leads to a higher degree of differentiation than with no cooperation.

${ }^{6} \mathrm{~A}$ recent example of joint process $\mathrm{R} \& \mathrm{D}$ as such is the cooperation between BMW Group and PSA Peugeot Citroën, which resulted in the development of a 1.4 liter petrol engine, which is an improved version of the existing 1.6 liter petrol engine the companies had developed jointly. The latter engine has already been launched within the car ranges of both partners. (Source: http://www.psa-peugeot-citroen.com)

${ }^{7}$ Most of the literature, including the seminal papers by Katz (1986) and D'Aspremont and Jacquemin (1988), consider cooperation in process R\&D. However, the issue has received some attention in the non-cooperative R\&D literature. See, for example, Athey and Schmutzler (1995) and Eswaran and Gallini (1996). There is a large set of other interesting questions that have been addressed so far, ranging from how private and social incentives for cooperation compare in different settings, e.g., in the presence of uncertainty, synergies, endogenous as well as exogenous spillovers, with and without an innovation race (see, among others, see Suzumura (1992), Choi (1993), Kamien et al (1992), and Kamien and Zang (2000)) to how cooperation may affect incentives to maintain post-innovation collusion (see
} 
and Saggi (2002) and Rosenkranz (2003), consider only the indirect link between the two decisions, which is their interaction through the competition stage. Considering the aforementioned direct link that is established by the firms' ability to engage in joint process R\&D only on the jointly developed product components also enables us to formally distinguish between joint and in-house investments in process R\&D. ${ }^{8}$

We first introduce a simple framework in which firms engage only in product development. We construct a duopoly model with an end-product, composed of distinct components, for which firms can engage in joint development. The degree of cooperation determines the degree of commonality (and hence, the degree of differentiation) in the two end-products. While firms share the cost of developing the common product components, they carry out independent research for the development of the remaining components. Therefore, a higher degree of cooperation (i.e., a higher degree of commonality) leads to savings in development costs, but it intensifies post-innovation competition by reducing the degree of differentiation between the competing end-products. A direct consequence is that no cooperation can be an equilibrium.

The main tradeoff we present in this section is also studied by Lambertini et al $(2002,2003)$ with a focus on the impact of RJVs on the sustainability of collusive agreements, ${ }^{9}$ and by Ghosh and Morita $(2006,2008)$ in the context of inter-firm platform sharing. Ghosh and Morita consider both the cost savings and the reduced degree of differentiation that result due to the use of the same platform -of a given size- by two firms. ${ }^{10}$ Different than Ghosh and Morita, in our model the degree of differentiation and the degree of cost savings due to joint product development are endogenous to firms' decisions on how much to cooperate on product development.

Next, we use a specific demand setting and bring process R\&D into the picture to study the interaction between product development and process $R \& D$. Once firms complete their product development, they invest in process $\mathrm{R} \& \mathrm{D}$, which reduces the cost of producing product components. We consider three scenarios: i) no-cooperation; ii) full-cooperation; and iii) partial-cooperation. For all three scenarios, we assume that firms decide on how much to cooperate in product development. Scenarios differ with respect to the process R\&D stage.

\footnotetext{
Martin (1996), Cabral (2000), and Lambertini et al (2002).

${ }^{8}$ To our knowledge there are only two papers that consider such a "hybrid" structure (i.e., joint and in-house investments) in process R\&D: Goyal et al. (2008) and Atallah (2004).

${ }^{9}$ Differently, they assume that formation of a RJV in product development produces completely identical products for two firms which would otherwise compete with differentiated products.

${ }^{10}$ Besides the cost savings in the development stage, the authors consider another advantage of platform sharing in their earlier paper: lower expected prices of procurement due to a larger number of potential suppliers for the shared components.
} 
Under the no-cooperation scenario, we assume that firms decide on their process $R \& D$ investments non-cooperatively. Under the full-cooperation scenario, we assume that firms cooperate in process $\mathrm{R} \& \mathrm{D}$ on all product components, and share the process $\mathrm{R} \& \mathrm{D}$ costs. These two scenarios are similar to the two scenarios considered by Lin and Saggi (2002); semi-cooperation and full-cooperation, respectively. ${ }^{11}$ Similar to Lin and Saggi (2002), we show that under both the no-cooperation and full-cooperation scenarios, the equilibrium process $R \& D$ investments decrease with the degree of joint product development. Furthermore, the equilibrium degree of cooperation in product development is higher when the marginal cost of component development and the marginal cost of process $\mathrm{R} \& \mathrm{D}$ are higher.

Under the partial-cooperation scenario, which is the novelty of this paper, firms cooperate in process $R \& D$ only partially. In particular, we assume that firms can engage in joint process $R \& D$ only on the product components that they have developed jointly. ${ }^{12}$ This assumption introduces a direct link between the degree of cooperation in product development and process $\mathrm{R} \& \mathrm{D}$ decisions, in addition to their interaction through the competition stage. In contrast with the no-cooperation and full-cooperation scenarios, we find that with partial-cooperation the degree of cooperation in product development can be lower when the process $\mathrm{R} \& \mathrm{D}$ cost is higher. Our major finding is that with partial cooperation the intensity of cooperation in process $R \& D$ (defined as relative process $\mathrm{R} \& \mathrm{D}$ investments in the common and non-common product components) decreases with the degree of cooperation in product development.

We also show that, for a given degree of cooperation in product development, the ordering of the equilibrium process $R \& D$ investments under different scenarios depend on the degree of product differentiation. For high degrees of product differentiation (soft competition in the product market), the process $R \& D$ investments are the highest under full-cooperation, and lowest under no-cooperation. The investments under the partial-cooperation scenario lie in between the two, and process $\mathrm{R} \& \mathrm{D}$ investments in the common components are higher than the investments in the non-common components. The reason is as follows; when competition is soft, the marginal return to process R\&D investments is high, and cost-sharing with cooperation leads to higher investments in the product components for which firms cooperate. For low degrees of differentiation, the ordering

\footnotetext{
${ }^{11}$ Except that firms do not share process R\&D costs in Lin and Saggi (2002).

${ }^{12}$ Cooperation in process R\&D is implicit when firms engage in joint production of the jointly developed product components, in particular when production is realized in one of the partners' facilities (for example, the 1.4 liter petrol engine is produced for both BMW and PSA Peugeot Citroën Groups at the PSA's plant in Douvrin). Since joint manufacturing of product components is also likely to involve economies of scale, which is not the focus of our paper, we assume that each firm produces product components separately.
} 
is reversed. This is because when competition in the product market is intense, firms tend to invest aggressively in process $\mathrm{R} \& \mathrm{D}$ for the product components that are not subject to cooperation, and they internalize this competition effect with the product components on which they cooperate.

The paper is organized as follows. In Section 2, we outline our basic model of cooperative product development and we highlight the factors that affect the degree of cooperation in product development in the absence of a process R\&D stage. In Section 3, we specify a demand setting, introduce process $\mathrm{R} \& \mathrm{D}$, and study the equilibrium degree of cooperation under the different scenarios. In Section 4 we simulate our model, and provide some welfare analysis. Finally, we conclude.

\section{A Model of Cooperative Product Development}

We consider an end-product that is composed of distinct product components, for which firms can engage in joint development. The degree of cooperation determines the degree of commonality in the competing end-products. While firms share the cost of developing the common product components, they develop the remaining product components independently.

The model we introduce here departs from the standard treatment of product development in two ways. First, cooperation in product development is not a zero-one decision; instead firms decide on the degree of cooperation, which also means that the economies obtained through joint product development vary with the degree of cooperation. Second, a higher degree of cooperation in product development implies a lower degree of differentiation and not the reverse. ${ }^{13}$ The adverse effect of cooperation on product differentiation leads to more intense competition, and hence constitutes a cost to cooperative product development.

\section{The setting}

There are two identical firms that are engaged in product development, which eventually compete in the product market with differentiated products. Once the products are developed, firms can produce at a constant marginal cost of $c$. Profit of firm $i$, gross of development cost, is denoted by $\pi_{i}(s)$, where $s$ stands for the degree of product differentiation, with $\partial \pi_{i} / \partial s \geq 0$ and $i=1,2$.

Product development The product is composed of a continuum of components, which is normalized to 1 . The marginal development cost of the $m^{\text {th }}$ component is denoted by $\eta(m)$. Letting

\footnotetext{
${ }^{13}$ See, for example, Lin and Saggi (2002), who find that the equilibrium level of product differentiation is higher under cooperation than with no cooperation.
} 
$d(m)$ denote the total cost of developing $m$ product components, we have

$$
d(m)=\int_{0}^{m} \eta(x) d x
$$

Cooperation in product development The firms jointly decide on the product components that they will jointly develop, that is, on the degree of commonality in their products, $\alpha$, with $\alpha \in[0,1]$.

The degree of commonality, $\alpha$, represents the degree of cooperation in product development; ${ }^{14}$ $\alpha=0$ corresponds to the case in which there is no cooperation, whereas $\alpha=1$ corresponds to the case in which the firms develop the entire product together. The degree of cooperation in product development determines both the product development costs and the degree of product differentiation.

i. Product development costs The firms share the development cost of common components, $d(\alpha)$, equally. Each firm also conducts in-house $\mathrm{R} \& \mathrm{D}$ to develop the remaining product components, for which each firm bears the full development cost. Therefore, for a given degree of cooperation $\alpha$, each firm has a product development cost of

$$
D(\alpha)=d(1)-\frac{d(\alpha)}{2}
$$

The first term in the right-hand side of equation (1) represents the total cost of product development, and the second term represents the savings obtained through joint development of product components. In our setting, the sole benefit of cooperation in product development is cost sharing, and there are no synergies from joint component development. ${ }^{15}$ Furthermore, we have $(d(1)-d(\alpha))+d(\alpha)=d(1)$, and hence, there are no economies (or diseconomies) of scope in developing the components.

ii. Degree of product differentiation The degree of differentiation between the firms' products, $s$, is determined by the degree of commonality, $\alpha$. We assume that $\partial s(\alpha) / \partial \alpha<0$, that is, the degree of differentiation decreases with the degree of commonality.

\footnotetext{
${ }^{14}$ We use the degree of cooperation in product development and the degree of commonality interchangeably throughout this paper.

${ }^{15}$ If one considers synergies in joint product development that are non-decreasing with the degree of cooperation, $\alpha$, one could also read $d(\alpha) / 2$ as the benefits obtained through the synergies.
} 


\section{The timing}

The firms first decide cooperatively on $\alpha$, and $s(\alpha)$ and $D(\alpha)$ are realized. Then, firms compete with prices and obtain a gross profit of $\pi_{i}(s(\alpha))$.

\section{The equilibrium}

We now characterize the equilibrium and highlight the main trade-off that is involved in firms' decisions on how much to cooperate in product development.

Given the symmetry of the firms, at the second stage, for a given degree of cooperation, $\alpha$, each firm obtains a gross profit of $\pi(s(\alpha))$. At the first stage, firms cooperatively set the degree of cooperation in product development so as to maximize their joint profits, which is tantamount to maximizing their individual profits:

$$
\max _{\alpha \in[0,1]} \pi(s(\alpha))-D(\alpha)
$$

The solution to this problem characterizes the equilibrium degree of cooperation, $\alpha^{*}$, which can be either a corner solution, i.e., no cooperation or full cooperation, or an interior solution, i.e., $\alpha^{*} \in(0,1)$. Since our focus is on the forces that affect the degree of cooperation, we restrict our analysis to an interior solution, and hence, begin by studying its existence.

The second order condition to the problem defined in (2) is

$$
\underbrace{\frac{\partial^{2} \pi(s)}{\partial s^{2}}\left(\frac{\partial s}{\partial \alpha}\right)^{2}}_{\mathrm{I}}+\underbrace{\frac{\partial \pi(s)}{\partial s} \frac{\partial^{2} s}{\partial \alpha^{2}}}_{\mathrm{II}}+\underbrace{\frac{1}{2} \frac{\partial^{2} d}{\partial \alpha^{2}}}_{\mathrm{III}}<0 .
$$

Since $(\partial s / \partial \alpha)^{2}>0$ and $\partial \pi(s) / \partial s \geq 0$, the signs of terms I and II are determined by the signs of $\partial^{2} \pi(s) / \partial s^{2}$ and $\partial^{2} s / \partial \alpha^{2}$, respectively. Notice that, with linear development and differentiation technologies, terms II and III vanish, and inequality (3) holds if and only if $\partial^{2} \pi(s) / \partial s^{2}<0$; we have an interior solution only if $\pi(s)$ is concave for some values of $s$. More generally, an interior solution exists if $\pi(s)$, and/or $s(\alpha)$ and/or $d(\alpha)$ is sufficiently concave. In the rest of the paper we assume that this is the case.

Given that there is an interior solution, the equilibrium degree of cooperation in product devel- 
opment is characterized by the first order condition,

$$
\frac{\partial \pi(s)}{\partial s} \frac{\partial s}{\partial \alpha}+\frac{1}{2} \frac{\partial d}{\partial \alpha}=0
$$

The first term in (4) is negative, whereas the second term is positive, which puts forth the following trade-off: a higher degree of cooperation implies greater savings in development costs (development cost effect), but at the same time a higher degree of commonality implies a lower degree of differentiation, which harms firms in the competition stage (competition effect).

Firms will choose to cooperate more in product development if the competition effect is mild relative to the development cost effect. The competition effect is mild if either the marginal effect of differentiation on profits is small, and/or the degree of commonality has a small marginal effect on the degree of differentiation. Therefore, we might expect to observe a high degree of cooperation in markets where product differentiation is not an important determinant of competition and/or in markets where product development costs are relatively large.

This simple trade-off is one potential explanation as to why firms do not cooperate on all product components in some product markets (if they cooperate at all). This trade-off has not been accounted for in the standard cooperation literature, in which firms are, at least weakly, better-off with (full) cooperation. As an exception, Ghosh and Morita $(2006,2008)$ consider similar costs (reduced differentiation) and benefits (cost sharing) of cooperation in the context of platform

sharing. Different from our setting, they consider firms that make binary choices -whether to share a platform or not. Allowing for continuous choices enables us to study the factors that might have an impact on the varying degree of cooperation between competing firms.

\section{Interaction between Product Development and Process R\&D}

In this section, we add a process $R \& D$ stage to our basic setting and study the interaction between product development and process R\&D by specifying the demand and cost functions. We consider three cooperation scenarios: no-cooperation (NC); full-cooperation (FC); and partial-cooperation (PC).

For all three scenarios, we assume that firms cooperate in product development and decide on the product components to be jointly developed. Scenarios differ with respect to cooperation in process R\&D.

Under the no-cooperation scenario, we assume that firms decide on their process R\&D invest- 
ments non-cooperatively. Under the full-cooperation scenario, we assume that firms cooperate in process $\mathrm{R} \& \mathrm{D}$ on all product components, and share the process $\mathrm{R} \& \mathrm{D}$ costs. In both scenarios, there is no direct link between the product development and process $\mathrm{R} \& \mathrm{D}$ decisions and they interact only through the competition stage. Our no-cooperation and full-cooperation scenarios are similar to the semi-cooperation and full-cooperation scenarios of Lin and Saggi (2002), except that Lin and Saggi do not consider cost-sharing in joint process R\&D investments. ${ }^{16}$ We also use the same demand specification as Lin and Saggi. Note, however, that our modeling of product development is different from theirs.

Finally, under the partial-cooperation scenario, which is not considered by Lin and Saggi (2002), firms cooperate in process $\mathrm{R} \& \mathrm{D}$ only partially. We assume that the firms can engage in joint process $\mathrm{R} \& \mathrm{D}$ only on the product components that they have developed jointly. This assumption introduces a direct link between the degree of cooperation in product development and process $\mathrm{R} \& \mathrm{D}$ decisions, which is the main novelty of our framework. We also assume that the firms share the cost of the joint process R\&D investments.

Demand Let the inverse demand for firm $i$ be defined by

$$
p_{i}=a-q_{i}-(1-s) q_{j}
$$

where $q_{i}$ and $p_{i}$ denote the quantity and price of firm $i$, with $i, j=1,2$ and $i \neq j$, and $s \in[\underline{s}, \bar{s}]$, with $\underline{s} \in(0, \bar{s})$ and $\bar{s} \leq 1$.

Process R\&D Process R\&D reduces the constant marginal cost of production. Firms decide how much to invest in process $\mathrm{R} \& \mathrm{D}$ for each product component. We assume that firm $i$ sets the same level of process R\&D investment, $x_{\alpha i}$, for all product components that are jointly developed with firm $j$ (i.e., for $\alpha$ components), and sets the same level of process R\&D investment, $x_{-\alpha i}$, for all components that it develops with in-house R\&D (i.e., for $(1-\alpha)$ components). ${ }^{17}$ The constant marginal cost of production of firm $i$ after process $\mathrm{R} \& \mathrm{D}$ is

\footnotetext{
${ }^{16}$ We adopt the same modeling approach as in the joint venture cartelization case in Kamien et al. (1992) and Rosenkranz (2003). Differently, other papers, e.g., d'Aspremont and Jacquemin (1988) and Lin and Saggi (2002), assume only coordination of $\mathrm{R} \& \mathrm{D}$ investments, and not cost-sharing (which is referred to as R\&D cartelization by Kamien et al.).

${ }^{17}$ We assume symmetric investments across jointly developed components and symmetric investments across noncommon components. One can assume away symmetry and show that the equilibrium indeed involves symmetric investments when the cost of process R\&D (taking into account potential cost-sharing) is the same across components. See Appendix A0 for the proof.
} 


$$
c_{i}=c-\alpha x_{\alpha i}-(1-\alpha) x_{-\alpha i}
$$

where $c$ denotes the constant marginal cost of production prior to any process R\&D investment. ${ }^{18}$ We assume that $c<a$.

The cost of conducting process $\mathrm{R} \& \mathrm{D}$ for firm $i$ is denoted by $R_{i}$ and is composed of two parts; $r_{\alpha i}\left(\alpha, x_{\alpha i}\right)$ and $r_{-\alpha i}\left(\alpha, x_{-\alpha i}\right)$ represent the costs of process R\&D investment for the common and non-common product components, respectively. We have

$$
R_{i}\left(\alpha, x_{\alpha i}, x_{-\alpha i}\right)=r_{\alpha i}\left(\alpha, x_{\alpha i}\right)+r_{-\alpha i}\left(\alpha, x_{-\alpha i}\right)=\rho_{\alpha} \psi \alpha \frac{x_{\alpha i}^{2}}{2}+\rho_{-\alpha} \psi(1-\alpha) \frac{x_{-\alpha i}^{2}}{2}
$$

with $\rho_{\alpha}=\rho_{-\alpha}=1$ under the no-cooperation scenario (i.e., each firm fully bears its cost of process R\&D investments for all components), $\rho_{\alpha}=\rho_{-\alpha}=1 / 2$ under the full-cooperation scenario (i.e., firms equally share the cost of process R\&D investments for all components), and $\rho_{\alpha}=1 / 2$ and $\rho_{-\alpha}=1$ under the partial-cooperation scenario (firms share the cost of process R\&D investments only for the common components). Finally, $\psi$ reflects the cost of process R\&D investments, and we assume that it is sufficiently high so that all second-order conditions for profit maximization hold. ${ }^{19}$

\section{The timing}

I. Product R\&D. Firms cooperatively decide on $\alpha$, the degree of cooperation in product development, and $s(\alpha)$ and $D(\alpha)$ are realized.

\section{Process R\&D.}

NC: Firms simultaneously and non-cooperatively set $x_{\alpha i}$ and $x_{-\alpha i}$.

FC: Firms simultaneously and cooperatively set $x_{\alpha i}$ and $x_{-\alpha i}$.

PC: Firms simultaneously and cooperatively set $x_{\alpha i}$ and non-cooperatively set $x_{-\alpha i}$.

\footnotetext{
${ }^{18}$ Our focus in this paper is the partial-cooperation scenario. In this scenario, the in-house process R\&D efforts are on the product components that are developed independently and they are less likely to entail spillovers. Therefore, we assume that one firm's independent process R\&D efforts $x_{-\alpha i}$ have no impact on the other firm's marginal cost of production, $c_{j}$.

${ }^{19}$ Under no cooperation, the lower bound on $\psi$ depends on the lower bound of the degree of differentiation, $\underline{s}$. Under full cooperation, the condition is $\psi>1$. Finally, under partial cooperation, the condition is $\psi>\max \{1, g(s)\}$ with $g(s) \in(0, \infty)$.
} 
Then, $R_{i}\left(\alpha, x_{\alpha i}, x_{-\alpha i}\right)$ and $c_{i}\left(\alpha, x_{\alpha i}, x_{-\alpha i}\right)$ are realized.

III. Competition. Firms compete with prices and profits are realized. ${ }^{20}$

In this setting, firms decide on joint and in-house process $R \& D$ investments once all product components (i.e., the end-products) are developed. ${ }^{21}$

\subsection{No-cooperation (NC) and Full-cooperation (FC)}

In this section, we analyze the NC and FC scenarios. In the NC scenario firms cooperate only at the product development stage, whereas in the FC scenario firms cooperate on all (common and non-common) product components at the process R\&D stage. We use superscripts NC and FC to distinguish between the scenarios.

Stages II and III - Process R\&D and Competition The profit functions at Stage III (competition stage) are identical in both scenarios and can be found in Appendix A1.

At stage II, under the NC scenario, the firms set process R\&D investments non-cooperatively on the common components, $x_{\alpha}$, and the non-common components, $x_{-\alpha}$, which corresponds to the semi-cooperation scenario of Lin and Saggi (2002). Hence, the analysis is similar and can be found in Appendix A1. The equilibrium process R\&D investments for each firm under the NC scenario are

$$
x_{\alpha}^{\mathrm{NC}}=x_{-\alpha}^{\mathrm{NC}}=x^{\mathrm{NC}}=\frac{2(a-c)\left(1+2 s-s^{2}\right)}{\psi(1+s)^{2}(3-s)(2-s)+2 s^{2}-4 s-2} .
$$

Differently, under the FC scenario, the firms set the process R\&D investments in the common components, $x_{\alpha}$, and the non-common components, $x_{-\alpha}$, cooperatively in order to maximize their joint profits at stage II. The equilibrium process R\&D investments for each firm are ${ }^{22}$

$$
x_{\alpha}^{\mathrm{FC}}=x_{-\alpha}^{\mathrm{FC}}=x^{\mathrm{FC}}=\frac{4 s(a-c)}{(2-s)(1+s)^{2} \psi-4 s} .
$$

\footnotetext{
${ }^{20}$ See Bourreau and Dogan (2007) for the analysis with Cournot competition.

${ }^{21}$ One could also consider an alternative timing in which firms first decide how much to cooperate on product and process $R \& D$, and then set their in-house process $R \& D$ investments. With this alternative timing, firms would be able to internalize the negative impact of competition in process $R \& D$ on the non-common components through their process $\mathrm{R} \& \mathrm{D}$ investments in the common components. Indeed, our analysis with such an alternative timing show that, firms choose lower process R\&D investments in the common components compared to the timing we consider in this paper. However, our simulations show that the difference in the equilibrium degree of cooperation in product development with different timings is insignificant. The analysis is available upon request from the authors.

${ }^{22}$ See Appendix A2.
} 
The following Proposition provides some comparative statics for both scenarios at Stage II and is identical to Part (i) of Proposition 2 of Lin and Saggi (2002), i.e., to the result they obtain for their semi-cooperation (our NC) scenario. ${ }^{23}$

Proposition 1 Under no-cooperation and full-cooperation scenarios, the equilibrium process RED investments are increasing with s.

\section{Proof. See Appendix A3.}

For a given degree of differentiation, the process $R \& D$ investment has a positive direct effect and a negative strategic effect on profits. The impact of the degree of differentiation on the magnitude of these effects is as follows. A higher degree of differentiation increases the magnitude of the positive direct effect as it shifts the demand outwards. At the same time, a higher degree of differentiation reduces the magnitude of the strategic effect, since the effect of a cost advantage on the equilibrium prices is lower with less intense competition. Therefore, a higher degree of differentiation implies higher investments in process $R \& D$ through a larger positive direct effect and a smaller negative strategic effect.

As a higher degree of cooperation in product $R \& D$ lowers the degree of differentiation, it leads to lower process R\&D investments, compared to the case in which firms do not cooperate in product development $(\alpha=0)$.

Finally, although the same comparative statics apply to both scenarios, we will show later that for any given level of $s$, each scenario yields different equilibrium levels of process R\&D investment.

Stage I - Product R\&D Firms set $\alpha$ to maximize their joint profits, which we denote by $\Pi_{J}^{\tau}$, with $\tau=\mathrm{NC}$, FC. Hence, the firms solve

$$
\max _{\alpha \in[0,1]} \Pi_{J}^{\tau}(\alpha)=\sum_{i=1}^{2} \pi_{i}^{\mathrm{III}, \tau}\left(s(\alpha), x^{\tau}(s(\alpha)), x^{\tau}(s(\alpha))\right)-R_{i}\left(x^{\tau}(s(\alpha))\right)-D(\alpha),
$$

where $\pi_{i}^{\mathrm{III}, \tau}\left(s(\alpha), x^{\tau}(s(\alpha)), x^{\tau}(s(\alpha))\right)$ is the equilibrium gross profit of firm $i$ in stage II and $x^{\mathrm{NC}}$ and $x^{\mathrm{FC}}$ are defined in equations (8) and (9). As in Section 2, we assume that $\Pi_{J}^{\tau}(\alpha)$ is concave, and we focus on the interior solution defined by the first-order condition.

\footnotetext{
${ }^{23}$ Note that $s$ in our setting corresponds to $(1-s)$ in the setting of Lin and Saggi (2002).
} 
Let $\pi_{J}^{\tau}$ denote the joint profits gross of process $\mathrm{R} \& \mathrm{D}$ costs and development costs. We have

$$
\pi_{J}^{\tau}\left(s, x_{1}, x_{2}\right)=\pi_{1}^{\mathrm{III}, \tau}\left(s, x_{1}, x_{2}\right)+\pi_{2}^{\mathrm{III}, \tau}\left(s, x_{1}, x_{2}\right) .
$$

Under the FC scenario, $x^{\mathrm{FC}}$ is set optimally to maximize joint profits at stage II. Therefore, by the envelope theorem, the first-order condition writes:

$$
\frac{d \Pi_{J}^{\mathrm{FC}}}{d \alpha}=\underbrace{\frac{\partial \pi_{J}^{\mathrm{FC}}\left(s, x^{\mathrm{FC}}, x^{\mathrm{FC}}\right)}{\partial s} \frac{\partial s}{\partial \alpha}}_{\text {competition effect }}+\eta(\alpha)=0
$$

Under the NC scenario, firms set $x^{\mathrm{FC}}$ independently at stage II, therefore, the first-order condition writes:

$$
\frac{d \Pi_{J}^{\mathrm{NC}}}{d \alpha}=\underbrace{\frac{\partial \pi_{J}^{\mathrm{NC}}\left(s, x^{\mathrm{NC}}, x^{\mathrm{NC}}\right)}{\partial s} \frac{\partial s}{\partial \alpha}}_{\text {competition effect }} \underbrace{+\frac{\partial \pi_{1}^{\mathrm{III}, \mathrm{NC}}}{\partial x_{-\alpha 2}} \frac{\partial x_{2}^{\mathrm{NC}}(s)}{\partial s} \frac{\partial s}{\partial \alpha}}_{\text {indirect strategic effect }} \underbrace{+\frac{\partial \pi_{2}^{\mathrm{III}, \mathrm{NC}}}{\partial x_{-\alpha 1}} \frac{\partial x_{1}^{\mathrm{NC}}(s)}{\partial s} \frac{\partial s}{\partial \alpha}}_{\text {indirect strategic effect }}+\eta(\alpha)=0
$$

Note that under both scenarios, apart from the last term $\eta(\alpha)$, which represents the marginal development cost, a higher degree of cooperation has only indirect effects on the firms' profits, which work through the degree of differentiation, $s$.

The competition effect, which is represented by the first terms of equations (11) and (12), is negative. A higher degree of cooperation in product development leads to a lower degree of differentiation, which in turn intensifies competition. Different than the FC scenario, under the NC scenario, there is an indirect strategic effect which is channeled through the impact of the degree of differentiation on the process R\&D investments of each firm. The second and the third terms in equation (12) represent this indirect strategic effect, which is positive. For any given firm, a lower degree of differentiation decreases the process $R \& D$ investments of the rival firm (from Proposition 1), which in turn increases the profits of the firm in question. Therefore, under the NC scenario, although the firms do not cooperate in process $R \& D$, they partially internalize the negative strategic effect of process $R \& D$ investments on profits by setting the degree of cooperation in product development in stage I. Under the FC scenario, these effects are absent in the first-order condition since firms fully internalize the negative strategic effect of process R\&D investments by setting the process R\&D investments jointly at stage II. Yet, we cannot conclude that firms cooperate more in product development under the NC scenario than under the FC scenario, since 
the competition effects under the two scenarios are computed for different values of process $R \& D$ investments.

In the following Proposition we characterize the equilibrium degree of cooperation for both scenarios.

Proposition 2 Under no-cooperation and full-cooperation, the equilibrium degree of cooperation in product development (i) is higher when the marginal cost of component development, $\eta($.$) , is$ higher, and (ii) increases with the cost of process RESD investments, $\psi$.

Proof. See Appendix A4.

The effect of development costs on the degree of cooperation in product development is straightforward; everything else being equal, a higher $\eta($.$) implies greater savings from cooperation in prod-$ uct development. ${ }^{24}$ This is true in both scenarios, as the marginal cost of component development is separable in the optimization problem.

Under both scenarios, the equilibrium degree of cooperation in product development increases with the cost of process $R \& D$ investments, but for different reasons. When firms cooperate in process $\mathrm{R} \& \mathrm{D}$, the only impact of $\psi$ on the equilibrium degree of cooperation in product development is through the competition effect (i.e., the direct effect of the degree of differentiation on joint profits), that is, through the profit margins. The responsiveness of profits to the degree of differentiation, and hence the marginal cost of cooperation in product development, varies with $\psi$. More precisely, a higher $\psi$ implies that firms' profits are less responsive to the degree of differentiation, hence, the magnitude of the direct effect is lower. To understand why, first consider the extreme case in which the degree of differentiation is zero. In this case, firms obtain zero profits regardless of their marginal cost, and hence, regardless of their joint investments in process R\&D. Now, consider the other extreme case in which firms are local monopolies. Then, profits are decreasing with marginal cost of production, and hence, with $\psi$. A higher $\psi$, therefore, implies a smaller profit margin for each firm, which in turn implies a lower marginal cost of cooperation in product development (i.e., a smaller negative marginal effect of the reduced degree of differentiation on firms' profits).

Under the NC scenario, the magnitude of the negative competition effect also decreases with $\psi$, for the same reasons as above. However, since firms compete in the process R\&D stage under this scenario, there are also indirect strategic effects. It turns out that the magnitudes of the positive indirect strategic effects also decrease with $\psi$. When $\psi$ is higher, firms compete less aggressively

\footnotetext{
${ }^{24}$ Note that, "a higher $\eta($.$) " corresponds to a function \eta_{1}($.$) , such that \eta_{1}(\alpha) \geq \eta(\alpha)$ for all $\alpha \in[0,1]$.
} 
in the process $R \& D$ stage, which in turn reduces the indirect effects of the degree of differentiation through process $\mathrm{R} \& \mathrm{D}$ investments. Ultimately, the impact of a higher $\psi$ on the competition effect dominates its impact on the indirect strategic effects, which is why the degree of cooperation increases with $\psi$ under the $\mathrm{NC}$ scenario.

Finally, Proposition 2 also implies that the degree of cooperation in product development is more likely to be high when firms cannot engage in process $R \& D$, for example, because of a prohibitively high $\psi$. In such a case, the analysis would be the same as in Section 2.

\subsection{Partial-cooperation (PC)}

In this section, we assume that firms' ability to cooperate in process $R \& D$ depends on the degree of cooperation they had in product development. More precisely, we assume that firms can engage in joint cost reducing activities only on the common product components that they have jointly developed. For the non-common product components, firms can conduct in-house process R\&D. ${ }^{25}$

We solve the game backwards, starting from the competition stage. The equilibrium profits of firms at the final stage are the same as in the other scenarios, and can be found in Appendix A1.

Stage II - Process R\&D The firms set the per-component process R\&D investment in the common product components, $x_{\alpha}^{\mathrm{PC}}$, cooperatively in order to maximize their joint profits, $\Pi_{1}^{\mathrm{PC}}+$ $\Pi_{2}^{\mathrm{PC}}$. Simultaneously, each firm $i$ sets its per-component process R\&D investment in the noncommon components, $x_{-\alpha i}^{\mathrm{PC}}$, so as to maximize its own profit.

We find that process $\mathrm{R} \& \mathrm{D}$ investments in common and non-common product components of each firm constitute strategic complements; a higher process R\&D investment in the common components implies a higher process $R \& D$ investment in the non-common components. The equilibrium cooperative and in-house process R\&D investments for each firm $\operatorname{are}^{26}$

$$
x_{\alpha}^{\mathrm{PC}}=4 s(3-s) \widehat{\gamma}
$$

and

$$
x_{-\alpha}^{\mathrm{PC}}=2\left(1+2 s-s^{2}\right) \widehat{\gamma},
$$

\footnotetext{
${ }^{25}$ One could also consider the case in which firms engage in independent process R\&D on the jointly developed components in addition to their joint process R\&D. However, due to symmetry of the firms it would be suboptimal for firms to do so, and hence, we exclude this possibility at the outset.

${ }^{26}$ See Appendix A5.
} 
with

$$
\widehat{\gamma}=\frac{(a-c)}{\psi(1+s)^{2}(3-s)(2-s)+2 s^{2}-4 s-2+2 \alpha\left(s^{2}-4 s+1\right)} .
$$

We now analyze how the degree of cooperation in product development affects the equilibrium level of process $R \& D$ investments. The effect of the degree of cooperation in product development on the equilibrium process $R \& D$ investments can be decomposed in the following way:

$$
\frac{d x^{\mathrm{PC}}}{d \alpha}=\frac{\partial x^{\mathrm{PC}}}{\partial \alpha}+\frac{\partial x^{\mathrm{PC}}}{\partial s} \frac{\partial s}{\partial \alpha}
$$

where $x^{\mathrm{PC}}$ can be read either $x_{\alpha}^{\mathrm{PC}}$ or $x_{-\alpha}^{\mathrm{PC}}$. There are various effects that interact. The first term on the right hand side of equation (15) represents a direct effect; that is, it describes how the change in $\alpha$ affects the process $\mathrm{R} \& \mathrm{D}$ investment decisions through cost-sharing and coordination of process R\&D investments for a given $s$. The second term represents the indirect effect of $\alpha$ on process R\&D investments, which works through the degree of differentiation. A higher $\alpha$ implies a lower degree of differentiation, which in turn affects the process R\&D decisions. This is because the degree of differentiation affects the magnitudes of the direct and strategic effects of process R\&D on profits (which we have discussed under the NC and FC scenarios). With the following table, we summarize the sign of each effect. ${ }^{27}$

\begin{tabular}{|c|c|}
\hline Table $\mathbf{1}:$ Marginal effect of $\alpha$ on process R\&D investments \\
\hline $\begin{array}{c}\text { Direct effect } \\
\partial x^{\mathrm{PC}} / \partial \alpha\end{array}$ & $\begin{array}{c}\text { Indirect effect } \\
{ }^{\mathrm{PC}} / \partial s \times \partial s / \partial \alpha\end{array}$ \\
\hline \hline$(+) \quad$ if $s \geq \widetilde{s}$ & $(-)$ \\
$(-) \quad$ if $s<\widetilde{s}$ & \\
\hline
\end{tabular}

The sign of the indirect effect is always negative and the intuition follows that of Proposition 1. The sign of the direct effect is positive only if the degree of differentiation is sufficiently large. This is because the two sources of the direct effect, cost-sharing and coordination of investments, work in opposite directions. A higher $\alpha$ enables firms to engage in joint process $\mathrm{R} \& \mathrm{D}$ on more product components. On one hand, this tends to increase process R\&D investments in the common components through the positive effect of cost-sharing. On the other hand, it implies that competition in process $R \& D$ investments is softer (as firms cooperate on more product components), which in

\footnotetext{
${ }^{27}$ See Appendix A6 for details.
} 
turn tends to reduce the level of process $R \& D$ investments in the common components. When the degree of differentiation is sufficiently high (i.e., when product competition is soft), the latter effect is insignificant, and the former effect determines the sign of the direct effect. Since process R\&D investments in common and non-common components are strategic complements, the sign of the marginal effect of $\alpha$ on process $\mathrm{R} \& \mathrm{D}$ investments in the non-common components follows that of the marginal effect of $\alpha$ on process $R \& D$ investments in the common components.

The marginal effect of the degree of cooperation on process $R \& D$ investments is, therefore, ambiguous except for sufficiently low degrees of differentiation. For sufficiently low degrees of differentiation, both direct and indirect effects are negative, and process R\&D investments in both common and non-common product components decrease with the degree of cooperation in product development. For higher degrees of differentiation, however, the sign of the marginal effect depends on the values of $\psi$ and $\partial s / \partial \alpha$, and can be either negative or positive.

Although the impact of $\alpha$ on process $\mathrm{R} \& \mathrm{D}$ investments is ambiguous for higher degrees of product differentiation, it has an unambiguous impact on the intensity of cooperation in process $\mathrm{R} \& \mathrm{D}$, which we define as the ratio $x_{\alpha}^{\mathrm{PC}} / x_{-\alpha}^{\mathrm{PC}}$. The intensity of cooperation provides a measure of how per-component process $R \& D$ efforts compare for joint and in-house R\&D. The intensity of cooperation is 1 with full-cooperation, whereas it is zero with NC.

Proposition 3 Under partial-cooperation, the intensity of cooperation in process RED decreases with the degree of cooperation in product development.

Proof. See Appendix A7.

A higher degree of cooperation in product development lowers the degree of product differentiation, which in turn leads to more aggressive process R\&D investments. Since the process R\&D investments in the common components internalize this strategic effect and the investments in the non-common components do not, the ratio of process R\&D investments in common components to process $\mathrm{R} \& \mathrm{D}$ investments in non-common components is lower with a higher degree of cooperation in product development.

With the following Proposition, for a given degree of cooperation in product development, we compare the levels of process $\mathrm{R} \& \mathrm{D}$ investments in the common and non-common product components for all three scenarios. 
Proposition 4 For a given degree of cooperation in product development, $\alpha$, we have

$$
x^{F C} \geq x_{\alpha}^{P C} \geq x_{-\alpha}^{P C} \geq x^{N C}
$$

if $s>\widetilde{s}$, and the order is reversed if $s \leq \widetilde{s}$.

Proof. See Appendix A8.

First, note that the ordering of process R\&D investments under NC and FC scenarios depends on the value of $s$. This is because when $s$ is low (intense competition in the product market), firms tend to compete aggressively in process $R \& D$ investments, which leads to a higher investment level under the NC scenario (i.e., when all process $\mathrm{R} \& \mathrm{D}$ investments are realized in-house). For higher values of $s$ (soft competition in the product market), process $\mathrm{R} \& \mathrm{D}$ investments yield a higher marginal return due to a greater price-cost margin. Since firms share the cost of process R\&D investments under FC, this leads to a higher investment compared to the NC scenario.

The level of process R\&D investments under the PC scenario lies between the NC and FC scenarios. With $\mathrm{PC}$, the ordering of process $\mathrm{R} \& \mathrm{D}$ investments in the common and non-common components also depends on the degree of differentiation. The intuition is similar to that provided above. Under the PC scenario, firms undertake both joint and independent process R\&D investments. When $s$ is high, marginal returns of process R\&D investments are high for both common and non-common components. Since cost sharing applies only to the investments in the common components, process R\&D investments are higher for those components compared to those in noncommon components. ${ }^{28}$ When $s$ is low, firms aggressively invest in process R\&D in the components that they have independently developed, and coordinate on a lower level of process R\&D investment in the common components.

Note that this result does not hold when firms coordinate, but do not cooperate, in process R\&D. If firms were to set $x_{\alpha}$ cooperatively, without sharing the process R\&D investment $\operatorname{costs}^{29}$ the order would be

$$
x^{\mathrm{NC}} \geq x_{-\alpha}^{\mathrm{PC}} \geq x_{\alpha}^{\mathrm{PC}} \geq x^{\mathrm{FC}}
$$

for all $s$. This is because in the absence of cost sharing and spillovers, coordination on cost reduction investments has merely a collusive effect, which yields lower investments compared to the case in

\footnotetext{
${ }^{28}$ Note that the cost sharing effect would be even stronger if one accounts for some synergies, which reduce the marginal cost of joint investments.

${ }^{29}$ This is called "R\&D cartelization" by Kamien et al. (1992).
} 
which firms decide non-cooperatively.

Stage I - Product R\&D Firms set $\alpha$ to maximize their joint profits,

$\Pi_{J}^{\mathrm{PC}}(\alpha)=\sum_{i=1}^{2} \pi_{i}^{\mathrm{III}, \mathrm{PC}}\left(s(\alpha), \alpha, x_{\alpha}^{\mathrm{PC}}(\alpha, s(\alpha)), x_{-\alpha}^{\mathrm{PC}}(\alpha, s(\alpha))\right)-R_{i}\left(\alpha, x_{\alpha}^{\mathrm{PC}}(\alpha, s(\alpha)), x_{-\alpha}^{\mathrm{PC}}(\alpha, s(\alpha))\right)-D(\alpha)$,

where $\pi_{i}^{\mathrm{III}, \mathrm{PC}}\left(s(\alpha), x_{\alpha}^{\mathrm{PC}}(\alpha, s(\alpha)), x_{-\alpha}^{\mathrm{PC}}(\alpha, s(\alpha))\right)$ is the equilibrium gross profit of firm $i$ in stage II and $x_{\alpha}^{\mathrm{PC}}$ and $x_{-\alpha}^{\mathrm{PC}}$ are defined in equations (13) and (14).

Let

$$
\pi_{J}^{\mathrm{PC}}\left(s(\alpha), \alpha, x_{\alpha}^{\mathrm{PC}}, x_{-\alpha 1}^{\mathrm{PC}}, x_{-\alpha 2}^{\mathrm{PC}}\right)=\sum_{i=1}^{2} \pi_{i}^{\mathrm{III}, \mathrm{PC}}\left(s(\alpha), \alpha, x_{\alpha}^{\mathrm{PC}}, x_{-\alpha 1}^{\mathrm{PC}}, x_{-\alpha 2}^{\mathrm{PC}}\right),
$$

and let $R_{J}=R_{1}+R_{2}$ denote the total process $\mathrm{R} \& \mathrm{D}$ costs. Since $x_{\alpha}^{\mathrm{PC}}$ is set so as to maximize the firms' joint profits, by the envelope theorem, the first-order condition is

$$
\frac{d \Pi_{J}^{\mathrm{PC}}}{d \alpha}=\frac{\partial \pi_{J}^{\mathrm{PC}}}{\partial s} \frac{\partial s}{\partial \alpha}+\frac{\partial \pi_{1}^{\mathrm{III}, \mathrm{PC}}}{\partial x_{-\alpha 2}} \frac{d x_{-\alpha}^{\mathrm{PC}}}{d \alpha}+\frac{\partial \pi_{2}^{\mathrm{III}, \mathrm{PC}}}{\partial x_{-\alpha 1}} \frac{d x_{-\alpha}^{\mathrm{PC}}}{d \alpha}+\frac{\partial \pi_{J}^{\mathrm{PC}}}{\partial \alpha}-\frac{\partial R_{J}}{\partial \alpha}+\eta(\alpha)=0
$$

which can be decomposed as

$$
\begin{aligned}
& \underbrace{\frac{\partial \pi_{J}^{\mathrm{PC}}}{\partial s} \frac{\partial s}{\partial \alpha}}_{\text {competition effect }} \underbrace{+\frac{\partial \pi_{1}^{\mathrm{III}, \mathrm{PC}}}{\partial x_{-\alpha 2}} \frac{\partial x_{-\alpha}^{\mathrm{PC}}}{\partial s} \frac{\partial s}{\partial \alpha}}_{\text {indirect strategic effect }} \underbrace{+\frac{\partial \pi_{2}^{\mathrm{II}, \mathrm{PC}}}{\partial x_{-\alpha 1}} \frac{\partial x_{-\alpha}^{\mathrm{PC}} \frac{\partial s}{\partial s} \frac{\partial s}{\partial \alpha}}{x^{2}}}_{\text {indirect strategic effect }}+\eta(\alpha) \\
& \underbrace{+\frac{\partial \pi_{1}^{\mathrm{III}, \mathrm{PC}}}{\partial x_{-\alpha 2}} \frac{\partial x_{-\alpha}^{\mathrm{PC}}}{\partial \alpha}}_{\text {direct strategic effect }} \underbrace{+\frac{\partial \pi_{2}^{\mathrm{III}, \mathrm{PC}}}{\partial x_{-\alpha 1}} \frac{\partial x_{-\alpha}^{\mathrm{PC}}}{\partial \alpha}}_{\text {direct strategic effect }} \underbrace{+\frac{\partial \pi_{J}^{\mathrm{PC}}}{\partial \alpha}}_{\text {direct MC effect direct R\&D cost effect }}=0 .
\end{aligned}
$$

Similar to the FC and NC scenarios, the competition effect is negative. Also, similar to the NC scenario, the indirect strategic effect ${ }^{30}$ is positive. This is because, as we know from our analysis for stage II, a lower degree of differentiation (due to a higher degree of cooperation in product development) leads to a lower level of process R\&D investments for the rival firm, which implies a higher profit for the firm in question.

Unlike the other scenarios, there are three direct effects under the PC scenario; a direct strategic effect, a direct marginal cost (MC) effect, and a direct $\mathrm{R} \& \mathrm{D}$ cost effect.

\footnotetext{
${ }^{30}$ Note that the second and the third terms, which represent this effect, are equal since they are computed in the symmetric equilibrium of the process R\&D subgame.
} 
The presence of the direct strategic effect is due to the direct link we have introduced in the PC scenario; the degree of cooperation in product development determines the degree of cooperation in the process $R \& D$ stage, since we assume that firms can carry joint process $R \& D$ only on the product components they have jointly developed. Therefore, different from the other scenarios, the degree of cooperation in product development under this scenario has a direct impact on the process in-house R\&D investments of a given firm, which then has an impact on the rival firm's profits. The sign of this direct strategic effect can either be negative or positive. As summarized in Table $1, \partial x_{-\alpha}^{\mathrm{PC}} / \partial \alpha$ is negative when $s$ is sufficiently small, and is positive otherwise. Therefore, the direct strategic effect is positive when $s$ is sufficiently small, and is negative otherwise.

Finally, there are two additional direct effects; a direct effect of $\alpha$ on joint gross profits (through marginal costs), and a direct effect of $\alpha$ on total process $\mathrm{R} \& \mathrm{D}$ costs, which are also absent in the $\mathrm{NC}$ and FC scenarios. These two effects have the same source. When $\alpha$ increases, the share of the total cost reduction (resp., total process R\&D costs), which is due to the joint process $R \& D$, increases. If $x_{\alpha}^{\mathrm{PC}}>x_{-\alpha}^{\mathrm{PC}}$, then a higher $\alpha$ will lead to a higher cost reduction (resp., total process $\mathrm{R} \& \mathrm{D}$ cost), ceteris paribus.

The direct MC effect of $\alpha$ on joint gross profits can be either positive or negative. A higher degree of cooperation in product development leads to a larger reduction in the marginal cost of production (due to a higher share of the joint process $R \& D$ ) if the joint process $R \& D$ investments are higher than the in-house $R \& D$ investments. From Proposition 4 , we know that this is true for sufficiently high values of $s$, and hence, the direct MC effect is positive only if $s$ is sufficiently high.

The direct R\&D cost effect of $\alpha$ on joint gross profits can also be either negative or positive. This is because a higher $\alpha$ has two opposite effects. First, when the degree of cooperation in product development is higher, firms carry more joint process $R \& D$, which tends to decrease their $R \& D$ costs due to cost sharing. However, when firms switch from in-house process R\&D to joint process $\mathrm{R} \& \mathrm{D}$ on some components (due to a higher $\alpha$ ), they also increase the amount of process R\&D on those components if $s$ is high (follows from Proposition 4). This second effect, in turn, tends to increase the total $\mathrm{R} \& \mathrm{D}$ costs. The first effect dominates the second, and hence the direct $\mathrm{R} \& \mathrm{D}$ cost effect is positive, for sufficiently low values of $s$, whereas the opposite is true for higher values of $s$.

In the following Proposition we characterize the equilibrium degree of cooperation.

Proposition 5 Under partial-cooperation, the equilibrium degree of cooperation in product development (i) is higher when the marginal cost of component development, $\eta($.$) , is higher, and (ii)$ 
can either increase or decrease with the cost of process RED investments, $\psi$.

Proof. See Appendix A9.

The process $\mathrm{R} \& \mathrm{D}$ cost, $\psi$, has a negative marginal impact on the magnitude of all the effects we have mentioned above.

Since the competition and indirect strategic effects are also present in the NC scenario, the qualitative nature of the analysis we have provided on the effect of $\psi$ on the equilibrium degree of cooperation in product development, $\alpha^{*}$, through these effects also holds in the PC scenario. First, a higher $\psi$ leads to a higher $\alpha^{*}$, as it decreases the magnitude of the (negative) competition effect. This is because a higher $\psi$ implies lower process $R \& D$ investments (immediate from equations (13) and (14)), which then implies a higher marginal cost of production in equilibrium. This, in turn, lowers the magnitude of the negative competition effect, which is present in all three scenarios. Second, similar to the reasons we have discussed under the NC scenario, the magnitude of the indirect strategic effects decreases with $\psi$.

Under the PC scenario, $\psi$ has an additional impact on $\alpha^{*}$, through its impact on the magnitudes of the direct (strategic, R\&D cost, and MC) effects that are absent in other scenarios.

The magnitude of the direct strategic effects can either increase or decrease with $\psi$, as there are two opposing underlying effects, cost-sharing and coordination of investment, that are discussed under the second stage analysis of the game.

The direct MC effect, when isolated from other effects, implies that a higher $\psi$, which reduces the magnitude of this effect, may lead to either a higher or a lower $\alpha^{*}$ depending on the degree of differentiation. If the degree of differentiation is sufficiently low, then the direct MC effect, which is negative (as the process $R \& D$ investments are higher in the non-common components than in the common components) is smaller in magnitude with a higher $\psi$, which leads to a higher $\alpha^{*}$. If the degree of differentiation is sufficiently large, than the direct $\mathrm{MC}$ effect is positive, and hence, a higher $\psi$ implies a lower $\alpha^{*}$.

Finally, a higher $\psi$ also reduces the magnitude of the direct R\&D cost effect, and may lead to either a lower or a higher $\alpha^{*}$ depending on the degree of differentiation. When $s$ is sufficienly low, a higher $\psi$ tends to decrease $\alpha^{*}$, and the reverse is true when the degree of differentiation is high.

As this analysis shows, accounting for a direct link between the cooperation decisions on product development and process $\mathrm{R} \& \mathrm{D}$ stages (our PC scenario) alters the findings of a setting in which such a link is absent (our NC and FC scenarios). First, we have process R\&D efforts decreasing with the degree of cooperation in product development under the FC and NC scenarios, whereas, the 
direction of this effect is ambiguous under the PC scenario. Second, although the equilibrium degree of cooperation in product development increases with the cost of process $R \& D$ efforts under the FC and NC scenarios, it can either increase or decrease under the PC scenario. This is because the direct link we have introduced in this scenario creates direct effects (strategic, MC, and R\&D cost) that are absent otherwise. These direct effects can work in the reverse direction of the competition effect (which dominates the indirect strategic effect in the absence of the direct effects). Finally, the direct link we consider in this scenario enables us to analyze cooperative process R\&D efforts relative to independent process $R \& D$ efforts. Our analysis suggests a substitutability between the degree of cooperation in product development and the intensity of cooperation in process R\&D.

Remark 1 The intensity of cooperation in process RED is lower for a higher $\eta($.$) , whereas it can$ either increase or decrease with $\psi$.

This remark follows directly from Propositions 3 and 5. We know that the intensity of cooperation in process $R \& D$ decreases with the degree of cooperation in product development (Proposition 3). We also know that the degree of cooperation in product development is higher when $\eta($.$) is$ higher, and that it can either increase or decrease with $\psi$. Therefore, a higher $\eta($.$) implies a higher$ degree of cooperation in product development, which in turn implies a lower intensity of cooperation in process R\&D. However, the impact of $\psi$ on the intensity of cooperation is ambiguous.

\section{Equilibrium degree of cooperation in product development and public policy}

In this section, we first discuss the economic forces that determine the equilibrium degree of cooperation and compare the equilibrium degree of cooperation under the three scenarios. We also provide a comparison of the equilibrium social welfare. We then provide a benchmark case in which cooperation in product development is banned $(\alpha=0)$, and compare the equilibrium process $\mathrm{R} \& \mathrm{D}$ investments, consumer welfare, and social welfare in the $\mathrm{NC}$ and $\mathrm{PC}$ scenarios to those in the benchmark case. We provide analytical results when possible, and revert to numerical simulations otherwise.

\subsection{Equilibrium degree of cooperation in product development}

We begin with a pair-wise comparison of the three scenarios. 
The equilibrium degree of cooperation in product development is higher under NC than under $\mathrm{FC}$, that is, $\alpha^{N C}>\alpha^{F C}$, unless the degree of differentiation is very low. ${ }^{31}$ Under both the NC and FC scenarios, there is no direct link between the two cooperation stages, and from Proposition 1, we know that the degree of product differentiation and process $R \& D$ investments are complements. From Proposition 4, we also know that the process R\&D investments under FC are higher than those under NC, unless the degree of differentiation is sufficiently low. Therefore, we might indeed expect the equilibrium degree of cooperation to be higher under NC than under FC, except for low degrees of differentiation.

The equilibrium degree of cooperation in product development can be either higher or lower under PC than under NC. This is because, on the one hand, the degree of cooperation has direct effects on profits under PC that are nonexistent under NC, and that are positive overall, which tends to lead to a higher degree of cooperation under PC. However, the sum of the competition effect and of the indirect strategic effects, which is negative, can be either higher or lower under PC than under NC, and hence the total effect is ambiguous. Depending on whether the former or the latter effects dominate, cooperation can be either lower or higher under PC compared to NC.

A similar argument applies for the comparison of the equilibrium degree of cooperation under the PC and FC scenarios, and hence, we can have either $\alpha^{P C}>\alpha^{F C}$, or the reverse.

Since it is not possible to provide a complete comparison analytically, we now revert to numerical simulations. We adopt the following functional form for the differentiation function, $s(\alpha)=\underline{s}+(\bar{s}-\underline{s})(1-\alpha)$, which satisfies our assumption, $\partial s(\alpha) / \partial \alpha<0$. We assume that $\eta(m)=\delta(1-m) / 2$, which implies that the marginal development cost decreases with $m$ (lower layers are more costly to develop than higher layers), and that $d(\alpha)=\delta\left(\alpha-\alpha^{2} / 2\right) / 2$. Without any loss of generality, we set $a=7$ and $c=2 .^{32}$

We run our simulations for $\{\underline{s}, \bar{s}, \psi\} \in\{0.1,0.2, \ldots, 0.5\} \times\{\underline{s}+0.1, \underline{s}+0.2, \ldots, \underline{s}+0.4\} \times\{5,5.1, \ldots, 15.0\} .{ }^{33}$

Our simulations show that when firms cooperate in product development in all three scenarios, we have ${ }^{34}$

$$
\alpha^{\mathrm{PC}}>\alpha^{\mathrm{NC}}>\alpha^{\mathrm{FC}}
$$

\footnotetext{
${ }^{31}$ The necessary condition for this is $s<0.208$. The proof is available upon request from the authors.

${ }^{32}$ This is because the parameter of interest in the first-order condition for the optimal $\alpha$ is $\delta /(a-c)^{2}$.

${ }^{33}$ We also ran our simulations for two alternative specifications: (i) $s(\alpha)=\underline{s}+(\bar{s}-\underline{s})(1-\alpha)^{1 / 2}$, and $d(\alpha)=\delta \alpha$; (ii) $s(\alpha)=\underline{s}+(\bar{s}-\underline{s})(1-\alpha)^{1 / 2}$ and $d(\alpha)=\delta\left(\alpha-\alpha^{2} / 2\right) / 2$. With specification (i), the adverse effect of componentsharing on differentiation is more important for high layers (high $\alpha$ ) than for low layers (low $\alpha$ ), whereas the marginal development cost is constant. Specification (ii) is a mix of our main specification and specification (i). Our results presented in this section are robust to these two alternative specifications.

${ }^{34}$ With our specification, and for all parameter values, the profit function is concave in $\alpha$.
} 
Note that this ordering may be violated when one considers a very low degree of differentiation, in which case we know that $\alpha^{\mathrm{FC}}>\alpha^{\mathrm{NC}}$, and that $\alpha^{\mathrm{PC}}$ can be either lower or higher than the equilibrium degree of cooperation in the two other scenarios.

\section{Thresholds of $\delta$ for a positive degree of cooperation and for no product development}

When studying the equilibrium degree of cooperation in product development, we have ruled out the case where firms do not cooperate at all in this stage. However, given that firms jointly set the optimal degree of cooperation, they will choose to cooperate only if cooperation brings a higher profit than when they develop their products independently. A major determinant of this decision is the cost of product development, $\delta$. In our setting, a higher $\delta$ increases the likelihood of cooperation, as it increases the marginal benefit of cooperation through cost sharing. Let $\delta^{\tau}(\psi)$ denote the minimum value of $\delta$, such that there is a strictly positive degree of cooperation in product development in the equilibrium of scenario $\tau$, that is, we have $\alpha^{\tau}(\delta, \psi)>0$, with $\tau=\mathrm{NC}, \mathrm{FC}, \mathrm{PC}$. An interesting question is then, how the threshold of $\delta$ compares under the three scenarios. In other words, under which scenario should we expect to observe cooperation in product development more often?

From Propositions 2 and 5, we know that the equilibrium degree of cooperation in product development increases with $\delta$ under all scenarios. Therefore, the ordering of the equilibrium degree of cooperation in product development that we obtain with our simulations (inequality 17) also implies that

$$
\delta^{F C}(\psi)>\delta^{N C}(\psi)>\delta^{P C}(\psi)
$$

which is confirmed by our simulations. The figure below illustrates our simulation results for the equilibrium degree of cooperation in the $\mathrm{NC}, \mathrm{FC}$, and PC scenarios. 


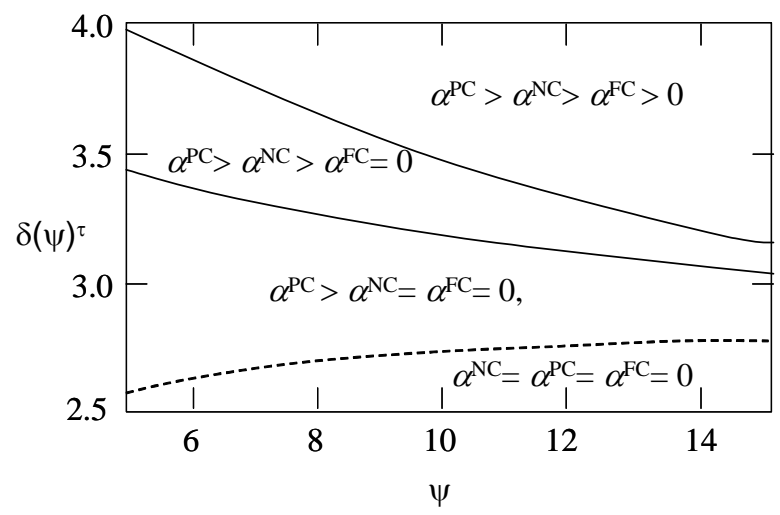

Cooperation in product development in the NC, PC, and FC scenarios, for $s \in[0.4,0.7]$.

Finally, when the cost of product development is sufficiently high, firms may obtain negative profits even if they do cooperate in product development and share the costs associated with it. Therefore, there exists a threshold $\delta$, above which the optimal degree of cooperation in product development yields negative profits to firms. Let $\bar{\delta}^{\tau}(\psi)$ denote this upper bound for $\delta$ in each scenario $\tau$, above which the equilibrium profit (for the equilibrium $\alpha$ ) is negative. By comparing $\bar{\delta}(\psi)$ under different scenarios, we can also determine how viable the product market is under the different scenarios.

Firms have the greatest flexibility under the FC scenario, in that they can replicate both the NC and PC process R\&D investments. Under the FC scenario, firms also share the costs associated with the process $R \& D$ investments, and hence, in equilibrium they make necessarily a higher profit than under the other scenarios. Similarly, firms make higher profits under the PC scenario than under the NC scenario (where there is neither cost-sharing nor coordination on process R\&D investments). Therefore, we have

$$
\bar{\delta}^{F C}(\psi)>\bar{\delta}^{P C}(\psi)>\bar{\delta}^{N C}(\psi)
$$

which is also confirmed by our simulations.

\section{Social Welfare under three scenarios}

The social welfare is given by $W=C S+\Pi_{1}+\Pi_{2}$, where $C S$ denotes the consumer surplus, which is given by $C S=\left(\left(q_{1}\right)^{2}+\left(q_{2}\right)^{2}+2(1-s) q_{1} q_{2}\right) / 2$, where $q_{i}$ denotes the quantity of firm $i$, and $\Pi_{1}$ and $\Pi_{2}$ are the firms' profits net of process $R \& D$ and product development costs.

The equilibrium of stage II is always symmetric, and hence we have $q_{1}=q_{2}=q$ at this stage. 
We find that

$$
q=\frac{a-\widetilde{c}}{(1+s)(2-s)}
$$

where $\widetilde{c}$ denotes the marginal cost post-process R\&D. Therefore, we have

$$
C S=(2-s) q^{2}=\frac{(a-\widetilde{c})^{2}}{(1+s)^{2}(2-s)}
$$

which implies that for a given $\alpha$ (hence, $s$ ), consumer surplus is higher when the cost-reduction is higher $(\widetilde{c}$ is lower $)$.

Under the NC and the FC scenarios we have $\widetilde{c}^{\tau}=c-x^{\tau}$, with $\tau=\mathrm{NC}, \mathrm{FC}$, whereas, under the PC scenario we have $\widetilde{c}=c-\alpha x_{\alpha}^{\mathrm{PC}}-(1-\alpha) x_{-\alpha}^{\mathrm{PC}}$. The expressions for consumer welfare and social welfare can be found in Appendix B1.

As consumer surplus (for a given $\alpha$ ) is higher when $\widetilde{c}$ is lower, it follows from Proposition 4 that

$$
C S^{\mathrm{FC}}(\alpha) \geq C S^{\mathrm{PC}}(\alpha) \geq C S^{\mathrm{NC}}(\alpha)
$$

for $s>\widetilde{s}$, and the order is reversed if $s \leq \widetilde{s}$. The intuition is the same as the one provided after Proposition 4. Since the equilibrium degree of cooperation in product development is different under different scenarios, we cannot expect inequality (19) to hold in the equilibrium.

Our simulations show that for $\underline{s} \in\{0.4,0.5\}$, inequality (19) also holds with the equilibrium degrees of cooperation in product development. This is also true for $\underline{s} \in\{0.1,0.2,0.3\}$ in more than 50 per cent of the cases.

Finally, when the market is viable under the three cooperation scenarios, ${ }^{35}$ our simulations show that the same ordering holds for the social welfare, i.e.,

$$
W^{\mathrm{FC}} \geq W^{\mathrm{PC}} \geq W^{\mathrm{NC}}
$$

unless $s$ is very low. ${ }^{36}$

\footnotetext{
${ }^{35}$ When the market is viable only under FC, then the social welfare is clearly higher under FC than in the two other scenarios.

${ }^{36}$ In our simulations, this is true whenever $\underline{s} \geq 0.2$. When $\underline{s}=0.1$, we find that the social welfare can be highest in any of the three scenarios.
} 


\subsection{Cooperation in Product Development and Public Policy}

In this section we ask whether policy makers should be concerned with the negative consequences of cooperation in product development between competing firms. ${ }^{37}$ To that end, we introduce a benchmark case in which firms are banned from cooperating in product development $(\alpha=0)$. We compare the process R\&D investments, the consumer welfare, and the social welfare in this benchmark with the equilibrium process $R \& D$ investments, the consumer welfare and the social welfare in the $\mathrm{NC}$ and $\mathrm{PC}$ scenarios. ${ }^{38}$

Since we are interested in the effect of allowing cooperation in product development, we assume (as in our model analysis) that there is indeed a strictly positive degree of cooperation in product development in the equilibrium when firms are free to set $\alpha$. Given this assumption, allowing cooperation in product development improves the industry profits in both scenarios. This is simply because when firms jointly set the degree of cooperation, they maximize the industry profits. The question is then, how does allowing cooperation in product development affect consumer welfare?

Recall that under our specification, the consumer surplus is given by equation (18), and that it depends both on post-process R\&D production costs and on the degree of differentiation.

Allowing cooperation in product development has two effects on the consumer surplus: a market competition effect, which is channeled through the degree of differentiation; and a production cost effect, which is channeled through the process R\&D investment decisions. In what follows, we study each effect individually.

Market competition effect Under both scenarios, allowing cooperation in product development reduces product differentiation, and hence, affects the consumer surplus in two opposite ways. A lower degree of differentiation hurts consumers as consumers value a greater variety, but at the same time it benefits consumers due to more intense competition in the product market. With our demand specification, the latter effect dominates the former, which means that, everything else equal, a higher degree of cooperation in product development increases consumer surplus.

Cost of production effect Consumer surplus increases with a lower cost of production postprocess R\&D investments. From Proposition 1, we know that in the NC scenario the process R\&D

\footnotetext{
${ }^{37}$ We thank one of the anonymous referees, who brought up this relevant question.

${ }^{38}$ When $\alpha=0$, the $\mathrm{NC}$ and PC scenarios lead to the same outcome, in which firms cooperate neither in product development nor in process R\&D. Hence, a comparison of the $\mathrm{NC}$ and $\mathrm{PC}$ scenarios when cooperation in product development is allowed proves to be meaningful, which is not true for the FC scenario.
} 
investments are decreasing with the degree of cooperation in product development. Hence, allowing cooperation in product development leads to a higher cost of production, which hurts consumer welfare.

From our analysis in Section 3.2, we know that in the PC scenario the process R\&D investments can either increase or decrease when we allow for cooperation in product development, except in cases with sufficiently low degrees of differentiation. When the degree of differentiation is sufficiently low, the effect of a higher $\alpha$ on process R\&D investments is negative, and the direction of this effect is ambiguous otherwise.

The overall effect on consumer surplus A priori, the overall effect of allowing cooperation in product development on consumer surplus is ambiguous in both scenarios, except for some special cases under the PC scenario. Under the PC scenario, a higher degree of cooperation in product development may lead to higher process $R \& D$ investments when the degree of differentiation is sufficiently high, and hence, to a higher consumer surplus.

Our computations for the NC scenario show that the consumer surplus increases with the degree of cooperation in product development if the degree of differentiation is sufficiently low. ${ }^{39}$ For the PC scenario, we find that the consumer surplus is higher when cooperation in product development is allowed versus when it is not, if the cost of process $R \& D$ investments is sufficiently high and/or the degree of differentiation is sufficiently low. When the cost of process R\&D investments is high, and when firms can cooperate in product development (which enables them to cooperate in process $\mathrm{R} \& \mathrm{D}$ as well), cost-sharing gives firms an additional incentive to invest in process $\mathrm{R} \& \mathrm{D}$, which in turn increases consumer welfare.

\section{Simulations of the variations in process $R \& D$ investments, consumer welfare and social} welfare Since our general analysis does not exclude the possibility that the consumer surplus may decrease upon allowing cooperation at the product development stage, the effect of such a policy on social welfare is ambiguous. We, therefore, revert to numerical simulations to determine the variation of consumer and social welfare when one allows for cooperation in product development.

Let $r_{W}^{\tau}$ denote the relative variation in social welfare when moving from the benchmark (no

\footnotetext{
${ }^{39}$ Indeed, the consumer surplus is decreasing with $s$ at $s=0$.
} 
cooperation at all) to the equilibrium in scenario $\tau$, with $\tau=\mathrm{NC}$, PC. That is, $r_{W}^{\tau}$ is defined as

$$
r_{W}^{\tau}=\frac{W^{\tau}\left(\alpha^{\tau}\right)-W^{\tau}(\alpha=0)}{W^{\tau}(\alpha=0)}
$$

We define similar ratios for the consumer surplus, and process R\&D investments, denoted by $r_{C S}^{\tau}$ and $r_{x}^{\tau}$, respectively. ${ }^{40}$ We run our simulations and compute the minimum, maximum and mean value ${ }^{41}$ of these ratios for $\{\underline{s}, \bar{s}\} \in\{0.1,0.2, \ldots, 0.5\} \times\{\underline{s}+0.1, \underline{s}+0.2, \ldots, \underline{s}+0.4\}, \psi \in$ $\{5,5.1, \ldots, 15.0\}$, and $\delta \in\left\{\delta^{\tau}(\psi), \delta^{\tau}(\psi)+0.1, \ldots, \bar{\delta}^{\tau}(\psi)\right\}$. The simulation results are summarized in the table below:

\begin{tabular}{|l|c|c|c|c|c|c|}
\hline \multicolumn{6}{|c|}{ Table 3: Relative variations in process R\&D, } \\
consumer surplus, and social welfare \\
\hline \multirow{2}{*}{} & \multicolumn{2}{|c|}{ No-cooperation } & \multicolumn{3}{c|}{ Partial-cooperation } \\
\cline { 2 - 7 } & $r_{W}^{\mathrm{NC}}$ & $r_{C S}^{\mathrm{NC}}$ & $r_{x}^{\mathrm{NC}}$ & $r_{W}^{\mathrm{PC}}$ & $r_{C S}^{\mathrm{PC}}$ & $r_{x}^{\mathrm{PC}}$ \\
\hline min & 0.00 & 0.00 & -0.09 & 0.00 & 0.00 & -0.26 \\
\hline max & 0.50 & 0.15 & 0.00 & 0.61 & 0.17 & 0.42 \\
\hline mean & 0.13 & 0.06 & -0.04 & 0.16 & 0.09 & 0.14 \\
\hline
\end{tabular}

Given the specifications of our model, allowing cooperation in product development increases the consumer welfare, and hence, the social welfare, under both scenarios for the entire range of parameters we have considered.

Under the NC scenario, although cooperation in product development lowers the process R\&D investments, it increases the consumer surplus, and hence, the social welfare, due to the intensified competition in the product market. Under the PC scenario, there are two additional effects due to the direct link between cooperation decisions at the product development and process R\&D stages. First, allowing cooperation in product development in this scenario can increase the process R\&D investments due to cost-sharing. Second, since the equilibrium degree of cooperation is higher under the PC scenario, a lower equilibrium degree of differentiation reinforces the market competition effect, which in turn benefits consumers.

Note that our results hinge on the demand specification we have adopted, with which consumers value price competition more than variety. In markets where consumers have a relatively higher

\footnotetext{
${ }^{40}$ In the partial cooperation scenario, we use the total cost reduction, which is defined as $\alpha x_{\alpha}^{\mathrm{PC}}+(1-\alpha) x_{-\alpha}^{\mathrm{PC}}$.

${ }^{41}$ The mean value is defined by the sum of all computed ratios divided by the number of computed ratios.
} 
valuation for variety, allowing cooperation in product development would decrease consumer surplus in the NC scenario. Differently, under the PC scenario, the effect on consumer surplus may remain positive, as an increase in the process $R \& D$ investments may offset the negative effect of reduced variety.

\section{Conclusion}

In this paper, we have provided a simple framework for cooperation in product development between competitors that puts forward the tradeoff between the benefits obtained through development cost sharing and the cost of intensified competition due to reduced product differentiation. A direct consequence is that no cooperation can be an equilibrium outcome. Our framework also differs from the standard treatment of $\mathrm{R} \& \mathrm{D}$ cooperation in that it allows for firms to jointly develop some product components, and not necessarily all. This enables us to study the factors that may have an impact on the degree of cooperation in product development both in the presence and in the absence of process R\&D.

We have also analyzed the interaction between cooperation decisions on product development and process R\&D. While doing so, we have considered a direct link between cooperation decisions in product development and process $\mathrm{R} \& \mathrm{D}$, and showed that the degree of cooperation in product development may adversely affect the intensity of cooperation in process $R \& D$.

All results, except for those stated in Propositions 1 and 4 hold under Cournot competition. Different from Bertrand competition, where the strategic effect of process R\&D investments on profits is negative, both direct and indirect (strategic) effects are positive with Cournot competition. For a given degree of differentiation, both no-cooperation and full-cooperation scenarios yield a higher equilibrium process R\&D investment under Cournot competition than under Bertrand competition. Furthermore, the equilibrium degree of cooperation in product development under Cournot competition is also higher than under Bertrand competition. For a given level of cooperation in product development, the partial-cooperation scenario with Cournot competition yields the following ordering for process $\mathrm{R} \& \mathrm{D}$ investments $x^{\mathrm{FC}} \geq x_{\alpha}^{\mathrm{PC}} \geq x_{-\alpha}^{\mathrm{PC}} \geq x^{\mathrm{NC}}$, which is also true with Bertrand competition, but only for high degrees of differentiation.

Finally, we ran numerical simulations to illustrate how introducing a direct link between two cooperation stages affects the likelihood of cooperation in product development, and the degree of cooperation, as well as the social welfare for specified differentiation and product development cost 
functions. Given our specifications, partial-cooperation yields the highest equilibrium degree of cooperation in product development. However, the social welfare under partial-cooperation lies in between the social welfare under full and no-cooperation. Society benefits most when firms jointly invest in process $\mathrm{R} \& \mathrm{D}$ on all product components (i.e., with full-cooperation).

We have adopted a duopoly setting in which the degree of cooperation in product development refers to the number of product components that are jointly developed. However, in an oligopolistic setting, the degree of cooperation may also involve another dimension, that is, the number of firms involved in joint development. One question is then, how the number of participants of an R\&D alliance relates to the number of product components that are developed within that alliance, which is left for future research. 


\section{References}

[1] d'Aspremont, C. and Jacquemin, A., 1988. Cooperative and Noncooperative R\&D in Duopoly with Spillovers. American Economic Review, Vol. 78(5), pp. 1133-37.

[2] d'Aspremont, C. and Jacquemin, A., 1990. Erratum. American Economic Review, Vol. 80, 1990, pp. 641-42.

[3] Atallah, G., 2004. The Allocation of Resources to Cooperative and Noncooperative R\&D. Australian Economic Papers, Vol. 43(4), pp. 435-47.

[4] Athey, S. and Schmutzler, A., 1995. Product and Process Flexibility in an Innovative Environment. Rand Journal of Economics, Vol. 26(4), pp. 557-74.

[5] Bourreau, M. and Dogan, P., 2007. Cooperation in Product Development and Process R\&D between Competitors. John F. Kennedy School of Government Faculty Research Working Paper Series, RWP07-056.

[6] Cabral, L. M. B, 2000. R\&D Cooperation and Product Market Competition. International Journal of Industrial Organization, Vol. 18(7), pp. 1033-47.

[7] Choi, J. P., 1993. Cooperative R\&D with Product Market Competition. International Journal of Industrial Organization, Vol. 11(4), pp. 553-71.

[8] Eswaran, M. and Gallini, N,. 1996. Patent Policy and the Direction of Technological Change. Rand Journal of Economics, Vol. 27(4), pp. 722-46.

[9] Ghosh, A. and Morita, H., 2008. An Economic Analysis of Platform Sharing. Journal the Japanese and International Economies, Vol. 22, pp. 164-186.

[10] Ghosh, A. and Morita, H., 2006. Platform Sharing in a Differentiated Duopoly. Journal of Economics \& Management Strategy, Vol. 15(2), pp. 397-429.

[11] Goyal, S., Moraga-González, J.L. and Konovalov, A., 2008. Hybrid R\&D, Journal of the European Economic Association, Vol. 6(6), pp. 1309-1338.

[12] Kamien, M. I., Muller, E., and Zang, I., 1992. Research Joint Ventures and R\&D Cartels. American Economic Review, Vol. 82(5), pp. 1293-306. 
[13] Kamien, M. I. and Zang, I., 2000. Meet me halfway: research joint ventures and absorptive capacity. International Journal of Industrial Organization, Vol. 18, pp. 995-1012.

[14] Katz, M. L., 1986. An Analysis of Cooperative Research and Development. Rand Journal of Economics, Vol 17(4), pp.527-43.

[15] Lambertini, L., Poddar, S., and Sasaki, D., 2003. RJVs in Product Innovation and Cartel Stability. Review of Economic Design, Vol. 7, pp.465-477.

[16] Lambertini, L., Poddar, S., and Sasaki, D., 2002. Research Joint Ventures, Product Differentiation, and Price Collusion. International Journal of Industrial Organization, Vol. 20(6), pp. $829-54$.

[17] Lin, P. and Saggi, K., 2002. Product Differentiation, Process R\&D, and the Nature of Market Competition. European Economic Review, Vol. 46(1), pp. 201-11.

[18] Martin, S., 1996. R\&D joint ventures and tacit product market collusion. European Journal of Political Economy, Vol. 11(4), pp. 733-41.

[19] Rosenkranz, S., 2003. Simultaneous choice of process and product innovation when consumers have a preference for product variety. Journal of Economic Behavior and Organization, Vol. 50(2), pp.183-201.

[20] Suzumura, K., 1992. Cooperative and Noncooperative R\&D in an Oligopoly with Spillovers. American Economic Review, Vol. 82(5), pp. 1307-20.

[21] Vilasuso, J. and Frascatore, M. R., 2000. Public Policy and R\&D When Research Joint Ventures Are Costly. Canadian Journal of Economics, Vol. 33(3), pp. 818-39. 


\section{Appendix}

\section{A0 Symmetric process R\&D investments}

Lemma 6 Consider a set $M=[\underline{m}, \bar{m}] \subset[0,1]$ of components of the product of a given firm, with $\bar{m}>\underline{m}$, and let $x(m)$ denote the process RED investment for common component $m$, for $m \in M$. Assume that the process $R \mathscr{B} D$ cost parameters are the same for all $m \in M$, that is, $\rho_{m}=\rho$ and $\psi_{m}=\psi$. Then, equilibrium process REDD investments satisfy $x(m)=x$ for all $m \in M$.

Proof. The total cost reduction and process R\&D cost are

$$
X=\int_{M} x(m) d m, \text { and } C=\int_{M} \rho \psi \frac{x(m)^{2}}{2} d m,
$$

respectively. Let

$$
\bar{x}=\frac{1}{\bar{m}-\underline{m}} \int_{M} x(m) d m
$$

be the average per-component investment. Setting $\bar{x}$ for each component $m \in M$ would yield the same total cost reduction, $X$ (and hence would not affect gross profits at the competition stage), and a total cost of process $R \& D$ of

$$
C^{\prime}=\int_{M} \rho \psi \frac{\bar{x}^{2}}{2} d m=\frac{\rho \psi}{2}(\bar{m}-\underline{m}) \bar{x}^{2} .
$$

The variance of $x(m)$ is

$$
\sigma^{2} \equiv \frac{1}{\bar{m}-\underline{m}} \int_{M}(x(m)-\bar{x})^{2} d m \geq 0,
$$

which can can also be expressed as

$$
\begin{aligned}
\sigma^{2} & =\frac{1}{\bar{m}-\underline{m}} \int_{M}\left(x(m)^{2}-2 \bar{x} x(m)+\bar{x}^{2}\right) d m \\
& =\frac{1}{\bar{m}-\underline{m}} \int_{M}\left(x(m)^{2}\right) d m-2 \bar{x} \times \frac{1}{\bar{m}-\underline{m}} \int_{M} x(m) d m+\bar{x}^{2} \\
& =\frac{1}{\bar{m}-\underline{m}} \int_{M}\left(x(m)^{2}\right) d m-\bar{x}^{2} .
\end{aligned}
$$


Since $\sigma^{2} \geq 0$, this proves that

$$
\frac{1}{\bar{m}-\underline{m}} \int_{M}\left(x(m)^{2}\right) d m \geq \bar{x}^{2},
$$

hence that

$$
C^{\prime}=\frac{\rho \psi}{2}(\bar{m}-\underline{m}) \bar{x}^{2} \leq \frac{\rho \psi}{2} \int_{M}\left(x(m)^{2}\right) d m=C .
$$

It is clear that this inequality is strict if $\sigma^{2}>0$, that is, if $x(m)$ is "dispersed". Therefore, starting from an asymmetric allocation of process $R \& D$ investment levels, the firm could maintain the same total cost reduction and decrease its total process $R \& D$ cost by averaging its investments across the set of components $M$, which would increase its profit. This proves that the equilibrium levels of investment are necessarily symmetric.

A1 No-cooperation. Let $\pi_{i}^{\sigma, \mathrm{NC}}$ denote the equilibrium gross profit of firm $i$ in stage $\sigma$, with $\sigma=\mathrm{II}, \mathrm{III}$.

Stage III $-p_{i}^{\mathbf{I I I}}$ and $\pi_{i}^{\mathrm{III}}$. At Stage 3 , firm $i$ maximizes $\pi_{i}^{\mathrm{NC}}=\left(p_{i}-c_{i}\right) q_{i}$ with respect to $p_{i}$, where $q_{i}$ is given by

$$
q_{i}=\frac{a s-p_{i}+(1-s) p_{j}}{s(2-s)}
$$

Replacing for $q_{i}$ in $\pi_{i}^{\mathrm{NC}}$, and computing first-order conditions (FOCs) and solving for the system yields Bertrand equilibrium prices,

$$
p_{i}^{\mathrm{III}}=\frac{\left(a s+c_{i}\right)(3-s)-(1-s)\left(c_{i}-c_{j}\right)}{(s+1)(3-s)},
$$

and profits,

$$
\pi_{i}^{\mathrm{III}, \mathrm{NC}}=\frac{\left(s(3-s)\left(a-c_{i}\right)+(1-s)\left(c_{j}-c_{i}\right)\right)^{2}}{s(1+s)^{2}(3-s)^{2}(2-s)}
$$

The same analysis applies for the FC and PC scenarios, and hence we have $\pi_{i}^{\mathrm{III}, \mathrm{NC}}=\pi_{i}^{\mathrm{III}, \mathrm{FC}}=$ $\pi_{i}^{\mathrm{III}, \mathrm{PC}}$.

Stage II $-x_{\alpha i}^{\mathrm{NC}}$ and $x_{-\alpha i}^{\mathrm{NC}} \quad$ For a given $\alpha$, firms simultaneously and non-cooperatively set $x_{\alpha i}^{\mathrm{NC}}$ and $x_{-\alpha i}^{\mathrm{NC}}$ to maximize

$$
\Pi_{i}^{\mathrm{NC}}=\pi_{i}^{\mathrm{III}, \mathrm{NC}}\left(\alpha, x_{\alpha i}^{\mathrm{NC}}, x_{-\alpha i}^{\mathrm{NC}}, x_{\alpha j}^{\mathrm{NC}}, x_{-a j}^{\mathrm{NC}}\right)-D(\alpha)-R_{i}\left(\alpha, x_{\alpha i}^{\mathrm{NC}}, x_{-\alpha i}^{\mathrm{NC}}\right),
$$


where $D(\alpha)$ and $R_{i}\left(\alpha, x_{\alpha i}^{\mathrm{NC}}, x_{-\alpha i}^{\mathrm{NC}}\right)$ are determined in equations (1) and (7). We replace (6) for $c_{i}$ and $c_{j}$, and $(20)$ for $\pi_{i}^{\mathrm{III}, \mathrm{NC}}$ in $\Pi_{i}^{\mathrm{NC}}$, and compute the first-order conditions with respect to $x_{\alpha i}^{\mathrm{NC}}$ and $x_{-\alpha i}^{\mathrm{NC}}$ for $i=1,2$. Solving for the four FOCs with four unknowns yields

$$
x_{\alpha}^{\mathrm{NC}}=x_{-\alpha}^{\mathrm{NC}}=x^{\mathrm{NC}}=\frac{2(a-c)\left(1+2 s-s^{2}\right)}{\psi(1+s)^{2}(3-s)(2-s)+2 s^{2}-4 s-2} .
$$

These values maximize the profit function if the Hessian matrix is symmetric negative definite, which is the case if

$$
\frac{2\left(s^{2}-2 s-1\right)^{2} \alpha^{2}}{(1+s)^{2}(3-s)^{2} s(2-s)}-\psi \alpha<0
$$

and

$$
\psi>\frac{2\left(s^{2}-2 s-1\right)^{2}}{(1+s)^{2}(3-s)^{2} s(2-s)}
$$

which is true for all $s$ if

$$
\psi>\frac{2\left(\underline{s}^{2}-2 \underline{s}-1\right)^{2}}{(1+\underline{s})^{2}(3-\underline{s})^{2} \underline{s}(2-\underline{s})} .
$$

Notice that the right-hand side of $(21)$ belongs to $(1 / 2, \infty)$. Finally, replacing for $x_{\alpha i}^{\mathrm{NC}}$ and $x_{-\alpha i}^{\mathrm{NC}}$ in $c_{i}$, and then replacing for $c_{i}$ in $\pi_{i}^{\mathrm{III}, \mathrm{NC}}$ yields

$$
\pi_{i}^{\mathrm{II}, \mathrm{NC}}=\pi_{j}^{\mathrm{II}, \mathrm{NC}}=\pi^{\mathrm{II}, \mathrm{NC}}=\frac{(a-c)^{2}(s+1)^{2}(3-s)^{2}(2-s) \psi^{2} s}{\left(\psi(2-s)(3-s)(s+1)^{2}+2 s^{2}-4 s-2\right)^{2}} .
$$

A2 Full-cooperation The gross profit of firm $i$ can be written as

$$
\pi_{i}^{\mathrm{III}, \mathrm{FC}}=\frac{s\left(a-\left(c-\alpha x_{\alpha}^{\mathrm{FC}}-(1-\alpha) \widetilde{x}_{-\alpha}\right)\right)^{2}}{(1+s)^{2}(2-s)} .
$$

Computing the FOCs for $x_{\alpha}^{\mathrm{FC}}$ and $x_{-\alpha}^{\mathrm{FC}}$, and solving the system of equations, we find

$$
x_{\alpha}^{\mathrm{FC}}=x_{-\alpha}^{\mathrm{FC}}=x^{\mathrm{FC}}=\frac{4 s(a-c)}{(2-s)(1+s)^{2} \psi-4 s} .
$$

This is a maximum if the Hessian matrix is symmetric definite negative, which is the case if

$$
\psi>\max \left\{\frac{4 s \alpha}{(2-s)(1+s)^{2}}, \frac{4 s}{(2-s)(1+s)^{2}}\right\}
$$


which is true for all $\alpha$ and $s$ if $\psi>1$. Replacing $x^{F C}$ for $\pi_{i}^{\mathrm{III}, \mathrm{FC}}$ yields

$$
\pi^{\mathrm{II}, \mathrm{FC}}=\frac{\psi^{2}(a-c)^{2} s(1+s)^{2}(2-s)}{\left(\psi(2-s)(1+s)^{2}-4 s\right)^{2}}
$$

A3 Proof of Proposition 1. Under NC, we have

$$
\frac{\partial x^{\mathrm{NC}}}{\partial s}=\frac{2 \psi(a-c)(s+1) \zeta(s)}{\left((2-s)(3-s)(1+s)^{2} \psi+2 s^{2}-4 s-2\right)^{2}}
$$

with $\zeta(s)=2 s^{4}-11 s^{3}+19 s^{2}-11 s+5$. We have sign $\partial x^{\mathrm{NC}} / \partial s=\operatorname{sign} \zeta(s)$ and we have $\zeta(s)>0$ for all $s \in[0,1]$. Under FC, we have

$$
\frac{\partial x^{\mathrm{FC}}}{\partial s}=\frac{8 \psi(a-c)(1+s)\left(s^{2}-s+1\right)}{\left[(2-s)(1+s)^{2} \psi-4 s\right]^{2}} .
$$

Since $s^{2}-s+1>0$ for all $s$, then $\partial x^{\mathrm{FC}} / \partial s>0$ for all $s$.

A4 Proof of Proposition 2. Let $\pi^{\mathrm{NC}}(s(\alpha))=\pi^{\mathrm{II}, \mathrm{NC}}(s(\alpha))-R\left(x^{\mathrm{NC}}(s(\alpha))\right)$. We start by proving that $\alpha^{\mathrm{NC}}$ increases with $\psi$. Since the firms make the same profit in the equilibrium of stage II, the degree of cooperation which maximizes the firms' joint profit also maximizes $\pi^{\mathrm{NC}}(s(\alpha))$. Therefore, the FOC can be written as

$$
\frac{d \Pi_{i}^{\mathrm{NC}}}{d \alpha}=\frac{\partial \pi^{\mathrm{NC}}}{\partial s}(\psi) \frac{\partial s}{\partial \alpha}-\frac{\partial D}{\partial \alpha}=0
$$

which can be rewritten as

$$
G\left(\alpha^{\mathrm{NC}}, \psi\right)=\frac{\partial \pi^{\mathrm{NC}}}{\partial s}(\psi) \frac{\partial s}{\partial \alpha}+\frac{1}{2} \frac{\partial d}{\partial \alpha}=0
$$

As

$$
\left.\frac{\partial G}{\partial \alpha}\right|_{\alpha=\alpha^{\mathrm{NC}}}<0
$$

due to the second-order condition (SOC), equation (22) implicitly defines a function $\alpha^{\mathrm{NC}}(\psi)$, and we have

$$
\frac{\partial \alpha^{\mathrm{NC}}(\psi)}{\partial \psi}=-\frac{\left.\frac{\partial G}{\partial \psi}\right|_{\alpha=\alpha^{\mathrm{NC}}}}{\left.\frac{\partial G}{\partial \alpha}\right|_{\alpha=\alpha^{\mathrm{NC}}}}
$$


Since

$$
\left.\frac{\partial G}{\partial \alpha}\right|_{\alpha=\alpha^{\mathrm{NC}}}<0, \text { we have } \operatorname{sign} \frac{\partial \alpha^{\mathrm{NC}}(\psi)}{\partial \psi}=\left.\operatorname{sign} \frac{\partial G}{\partial \psi}\right|_{\alpha=\alpha^{\mathrm{NC}}}
$$

We have

$$
\frac{\partial G}{\partial \psi}=\frac{\partial s}{\partial \alpha} \frac{\partial}{\partial \psi}\left(\frac{\partial \pi^{\mathrm{NC}}}{\partial s}(\psi)\right)
$$

and we have

$$
\frac{\partial}{\partial \psi}\left(\frac{\partial \pi^{\mathrm{NC}}}{\partial s}(\psi)\right)=f(\psi, s) \frac{-4 \psi(a-c)^{2}(1+s)^{2}(2-s)}{\left(\psi(2-s)(3-s)(s+1)^{2}+2 s^{2}-4 s-2\right)^{4}}
$$

with

$$
\begin{aligned}
f(\psi, s)= & (1+s)(3-s)\left(-2 s^{6}+20 s^{5}-71 s^{4}+110 s^{3}-76 s^{2}+22 s+13\right) \psi \\
& -28-16 s-32 s^{5}+60 s^{2}+4 s^{6}-112 s^{3}+92 s^{4} .
\end{aligned}
$$

Since $(1+s)(3-s)\left(-2 s^{6}+20 s^{5}-71 s^{4}+110 s^{3}-76 s^{2}+22 s+13\right)>0$ for all $s$, we have $f(\psi, s) \geq$ $f(1, s)$ for all $s$ and $\psi \geq 1$. We find that $f(1, s)>0$ for all $s$, hence,

$$
\frac{\partial}{\partial \psi}\left(\frac{\partial \pi^{\mathrm{NC}}}{\partial s}(\psi)\right)<0
$$

for all $s$ and for all $\psi>1$, and hence, $\partial \alpha^{\mathrm{NC}}(\psi) / \partial \psi>0$.

Now, we prove that $\alpha^{\mathrm{NC}}$ is higher when the marginal cost of component development, $\eta($.$) , is$ higher. Since the FOC can be written as

$$
\frac{\partial \pi^{\mathrm{NC}}}{\partial s} \frac{\partial s}{\partial \alpha}+\frac{1}{2} \eta(\alpha)=0
$$

due to the concavity of the profit function, a higher $\eta($.$) yields a higher degree of cooperation \alpha^{\mathrm{NC}}$.

Finally, we prove the proposition for the FC scenario. Let $\pi^{\mathrm{FC}}(s(\alpha))=\pi^{\mathrm{II}, \mathrm{FC}}(s(\alpha))-$ $R\left(x^{\mathrm{FC}}(s(\alpha))\right)$. The proof follows the proof for the NC scenario; using that

$$
\frac{\partial}{\partial \psi} \frac{\partial \pi^{\mathrm{FC}}}{\partial s}=-16 \psi(a-c)^{2} s(1+s) \frac{\left(s^{2}-s+1\right)}{\left((2-s)(1+s)^{2} \psi-4 s\right)^{3}}
$$

is negative. 
A5 Partial-cooperation Replacing for $c_{i}^{\mathrm{PC}}$ and $c_{j}^{\mathrm{PC}}$ into (20), the gross profit of firm $i$ can be rewritten as

$\pi_{i}^{\mathrm{III}, \mathrm{PC}}=\frac{\left(a s(3-s)-\left(1+2 s-s^{2}\right)\left(c-\alpha x_{\alpha}^{\mathrm{PC}}-(1-\alpha) x_{-\alpha i}^{\mathrm{PC}}\right)+(1-s)\left(c-\alpha x_{\alpha}^{\mathrm{PC}}-(1-\alpha) x_{-\alpha j}^{\mathrm{PC}}\right)\right)^{2}}{s(1+s)^{2}(3-s)^{2}(2-s)}$.

Computing the FOCs for $x_{\alpha}^{\mathrm{PC}}$ and $x_{-\alpha i}^{\mathrm{PC}}$ for $i=1,2$, and solving the system of equations, we find $x_{\alpha}^{\mathrm{PC}}$ and $x_{-\alpha}^{\mathrm{PC}}$ as defined in (13) and (14), respectively. SOCs for $x_{\alpha}^{\mathrm{PC}}$ and $x_{-\alpha}^{\mathrm{PC}}$, which can be rewritten as

$$
\psi>\frac{4 \alpha s}{(2-s)(1+s)^{2}}, \text { and } \psi>\frac{2(1-\alpha)\left(s^{2}-2 s-1\right)^{2}}{(2-s)(1+s)^{2}(3-s)^{2} s}
$$

respectively, hold for

$$
\psi>\max \left\{1, \frac{2(1-\alpha)\left(s^{2}-2 s-1\right)^{2}}{(2-s)(1+s)^{2}(3-s)^{2} s}\right\} .
$$

A6 Variations of $x_{\alpha}^{\mathrm{PC}}$ and $x_{-\alpha}^{\mathrm{PC}}$ with respect to $\alpha$ For the common components, we have

$$
\begin{aligned}
\frac{d x_{\alpha}^{\mathrm{PC}}}{d \alpha}= & \frac{8(a-c) s(3-s)\left(4 s-1-s^{2}\right)}{\left(\psi(1+s)^{2}(3-s)(2-s)+2 s^{2}-4 s-2+2 \alpha\left(s^{2}-4 s+1\right)\right)^{2}} \\
& +\frac{8(a-c)\left((s+1)(3-s)^{2}\left(s^{2}-s+1\right) \psi-(1-\alpha)\left(s^{2}-2 s+3\right)\right)}{\left(\psi(1+s)^{2}(3-s)(2-s)+2 s^{2}-4 s-2+2 \alpha\left(s^{2}-4 s+1\right)\right)^{2}} \frac{\partial s}{\partial \alpha} .
\end{aligned}
$$

The first term is positive if $4 s-1-s^{2}>0$, that is, if $s>\widetilde{s}$, where $\widetilde{s}=2-\sqrt{3} \approx 0.268$. The second term is always negative, as $(s+1)(3-s)^{2}\left(s^{2}-s+1\right) \psi-(1-\alpha)\left(s^{2}-2 s+3\right)>0$ for all $s$ when $\psi>1$ (required by the SOC at stage 2). For the non-common components we have

$$
\begin{aligned}
\frac{d x_{-\alpha}^{\mathrm{PC}}}{d \alpha}= & \frac{4(a-c)\left(s^{2}-2 s-1\right)\left(s^{2}-4 s+1\right)}{\left(\psi(1+s)^{2}(3-s)(2-s)+2 s^{2}-4 s-2+2 \alpha\left(s^{2}-4 s+1\right)\right)^{2}} \\
& +(a-c) \frac{\left(2(s+1)\left(2 s^{4}-11 s^{3}+19 s^{2}-11 s+5\right) \psi+8 \alpha\left(s^{2}-2 s+3\right)\right)}{\left(\psi(1+s)^{2}(3-s)(2-s)+2 s^{2}-4 s-2+2 \alpha\left(s^{2}-4 s+1\right)\right)^{2}} \frac{\partial s}{\partial \alpha} .
\end{aligned}
$$

The first term is positive if $s^{2}-4 s+1<0$, that is, if $s>\widetilde{s}$. The second term is negative as $2(s+1)\left(2 s^{4}-11 s^{3}+19 s^{2}-11 s+5\right) \psi+8 \alpha\left(s^{2}-2 s+3\right)>0$ for all $s$ and $\psi$.

A7 Proof of Proposition 3. It is straightforward, since we have $x_{\alpha}^{\mathrm{PC}} / x_{-\alpha}^{\mathrm{PC}}=2 s(3-s) /\left(1+2 s-s^{2}\right)$, which is an increasing function of $s$, and we have $\partial s / \partial \alpha<0$. 
A8 Proof of Proposition 4. With NC, the process R\&D investment per-component is

$$
x^{\mathrm{NC}}=\frac{2(a-c)\left(1+2 s-s^{2}\right)}{\psi(1+s)^{2}(3-s)(2-s)+2 s^{2}-4 s-2},
$$

whereas with $\mathrm{PC}$ it is

$$
x_{\alpha}^{\mathrm{PC}}=\frac{(a-c) \times 4 s(3-s)}{\psi(1+s)^{2}(3-s)(2-s)+2 s^{2}-4 s-2+2 \alpha\left(s^{2}-4 s+1\right)}
$$

for the common components, and

$$
x_{-\alpha}^{\mathrm{PC}}=\frac{(a-c) \times 2\left(1+2 s-s^{2}\right)}{\psi(1+s)^{2}(3-s)(2-s)+2 s^{2}-4 s-2+2 \alpha\left(s^{2}-4 s+1\right)} .
$$

for the non-common components. First, we have $x_{\alpha}^{\mathrm{PC}} \geq x_{-\alpha}^{\mathrm{PC}}$ if and only if $4 s(3-s) \geq 2\left(1+2 s-s^{2}\right)$, which is equivalent to $s \geq \widetilde{s}$. Second, we have $x_{-\alpha}^{\mathrm{PC}} \geq x^{\mathrm{NC}}$ if and only if $2 \alpha\left(s^{2}-4 s+1\right) \leq 0$, which is equivalent to $s \geq \widetilde{s}$. Finally, we have

$$
x^{\mathrm{FC}}=\frac{4 s(a-c)}{\psi(1+s)^{2}(2-s)-4 s},
$$

and

$$
x_{\alpha}^{\mathrm{PC}}=\frac{4 s(a-c)}{\psi(1+s)^{2}(2-s)+\left[2 s^{2}-4 s-2+2 \alpha\left(s^{2}-4 s+1\right)\right] /(3-s)} .
$$

We have $x^{\mathrm{FC}}>x_{\alpha}^{\mathrm{PC}}$ if and only if $4 s>-\left[2 s^{2}-4 s-2+2 \alpha\left(s^{2}-4 s+1\right)\right] /(3-s)$, which is true if and only if $2(1-\alpha)\left(s^{2}-4 s+1\right)<0$, that is, $s>\widetilde{s}$.

A9 Proof of Proposition 5. We use a reduced form for the profit function. Let $\pi^{\mathrm{PC}}(\alpha, s)=$ $\pi^{\mathrm{II}, \mathrm{PC}}(\alpha, s)-R\left(\alpha, x_{\alpha}^{\mathrm{PC}}(\alpha, s), x_{-\alpha}^{\mathrm{PC}}(\alpha, s)\right)$. Since the equilibrium of the second stage subgame is symmetric, each firm making $\pi^{\mathrm{PC}}(\alpha, s)$, maximizing joint profits with respect to $\alpha$ is equivalent to maximizing $\pi^{\mathrm{PC}}(\alpha, s)$. The FOC can be written as

$$
\frac{d \Pi_{i}^{\mathrm{PC}}}{d \alpha}=\frac{\partial \pi^{\mathrm{PC}}}{\partial \alpha}+\frac{\partial \pi^{\mathrm{PC}}}{\partial s} \frac{\partial s}{\partial \alpha}+\frac{1}{2} \eta(\alpha)=0
$$

The first term (a direct effect) corresponds to the sum of the direct effects in (16). Whereas, the second term (an indirect term) corresponds to the sum of the indirect effects in (16). We analyze the effect of $\psi$ on these direct and indirect effects of $\alpha$ on profit (first term and second term of the 
FOC above). The direct effect is given by

$$
\frac{\partial \pi^{\mathrm{PC}}}{\partial \alpha}=2 \psi(a-c)^{2} \frac{f(s, \psi, \alpha)}{\left[\left((2-s)(3-s)(1+s)^{2} \psi+2 \alpha\left(1+s^{2}\right)+2\left(s^{2}-2 s-4 s \alpha-1\right)\right)\right]^{3}} .
$$

The denominator is positive for all $s, \alpha$, and $\psi$, as it has the same sign as $x_{\alpha}^{\mathrm{PC}}$ and $x_{\alpha}^{\mathrm{PC}} \geq 0$ necessarily. The numerator increases with $\psi$. When $\psi=1$, it becomes a function of $s$ and $\alpha$ defined on the closed cube $[0,1]^{2}$. It can be shown that the minimum of this function on $[0,1]^{2}$ is equal to 0 (for $s=\alpha=1$ ), hence that it is positive. Therefore, for all $\psi \geq 1$ and all $s$ and $\alpha$, we have $\partial \pi^{\mathrm{PC}} / \partial \alpha \geq 0$, that is, the direct effect is positive.

Now, we study the variation of $\partial \pi^{\mathrm{PC}} / \partial \alpha$ with respect to $\psi$. We have

$$
\frac{\partial}{\partial \psi} \frac{\partial \pi^{\mathrm{PC}}}{\partial \alpha}=-2 \frac{g(s, \psi, \alpha)}{\left[\left((2-s)(3-s)(1+s)^{2} \psi+2 \alpha\left(1+s^{2}\right)+2\left(s^{2}-2 s-4 s \alpha-1\right)\right)\right]^{4}},
$$

where $g(\psi, s, \alpha)$ is a second-degree polynomial in $\psi$. The term in $\psi^{2}$ of $g$ is a function of $s$ only, and for all $s \in[0,1]$ it is strictly positive; hence, $g$ is inverted bell-shaped. The highest root of $g$ is a function of $s$ and $\alpha$ over the closed cube $[0,1]^{2}$; hence, we can determine its maximum for $(s, \alpha) \in$ $[0,1]^{2}$, which is equal to 1 . Since $\psi>1$ (required by the SOC at stage 2 ), this proves that $g$ is positive for all $s$ and $\alpha$ and $\psi>1$, hence that $\partial\left(\partial \pi^{\mathrm{PC}} / \partial \alpha\right) / \partial \psi<0$, which means that the direct effect decreases with $\psi$.

The indirect effect is given by $\left(\partial \pi^{\mathrm{PC}} / \partial s\right)(\partial s / \partial \alpha)$. The second term in this expression is always negative and is independent of $\psi$. Therefore, we study the sign of $\partial \pi^{\mathrm{PC}} / \partial s$ and its variation with respect to $\psi$. We have

$$
\frac{\partial \pi^{\mathrm{PC}}}{\partial s}=2 \psi(a-c)^{2} \frac{h(\psi, s, \alpha)}{\left[\left((2-s)(3-s)(1+s)^{2} \psi+2 \alpha\left(1+s^{2}\right)+2\left(s^{2}-2 s-4 s \alpha-1\right)\right)\right]^{3}} .
$$

The denominator is strictly positive if $\psi>1$. The numerator has the opposite sign of $h$, and $h$ is a second degree-polynomial in $\psi$. The factor in $\psi^{2}$ is equal to $(1+s)^{3}(3-s)^{3}(2-s)\left(s^{2}-s+1\right)$, which is strictly positive, hence $h$ is inverted bell-shaped. The highest root of $h$ (if it exists) is a function of $\alpha$ and $s$. We compute the maximum of this root for $(\alpha, s) \in[0,1]^{2}$, and we find that this maximum is equal to 1 . Therefore, since $\psi>1$ by the SOC, we have $\partial \pi^{\mathrm{PC}} / \partial s>0$ for all $\psi$, $\alpha$ and $s$. It follows that the indirect effect is always negative. 
To determine the variations of $\partial \pi^{\mathrm{PC}} / \partial s$ with respect to $\psi$, we compute

$$
\frac{\partial}{\partial \psi} \frac{\partial \pi^{\mathrm{PC}}}{\partial s}=(a-c)^{2} \frac{k(\psi, s, \alpha)}{\left[\left((2-s)(3-s)(1+s)^{2} \psi+2 \alpha\left(1+s^{2}\right)+2\left(s^{2}-2 s-4 s \alpha-1\right)\right)\right]^{4}}
$$

where $k$ is a second-degree polynomial in $\psi$. Since the term in $\psi^{2}$ is strictly negative for all $s$ and $\alpha$, then $k$ is bell-shaped. We determine the maximum of $k$ for $(\alpha, s) \in[0,1]^{2}$, and

$$
\psi>\max \left\{1, \frac{2(1-\alpha)\left(s^{2}-2 s-1\right)^{2}}{(2-s)(1+s)^{2}(3-s)^{2} s}\right\} .
$$

We find that the maximum is equal to 0 . Therefore, for all $(\alpha, s) \in[0,1]^{2}$ and

$$
\psi>\max \left\{1,2(1-\alpha)\left(s^{2}-2 s-1\right)^{2} /\left((2-s)(1+s)^{2}(3-s)^{2} s\right)\right\}
$$

we have $k \leq 0$, hence $\partial\left(\partial \pi^{\mathrm{PC}} / \partial s\right) / \partial \psi \leq 0$, which implies that the indirect effect increases with $\psi$.

B1 Consumer welfare and social welfare For a given $\alpha$, consumer welfare and and social welfare under three scenarios are as follows:

$$
\begin{gathered}
C S^{\mathrm{NC}}=\frac{(2-s)(3-s)^{2}(1+s)^{2}(a-c)^{2} \psi^{2}}{\left[\psi(1+s)^{2}(3-s)(2-s)+2 s^{2}-4 s-2\right]^{2}}, \\
W^{\mathrm{NC}}=(a-c)^{2} \psi^{2} \frac{(1+2 s)(2-s)(1+s)^{2}(3-s)^{2} \psi-4\left(1+2 s-s^{2}\right)^{2}}{\left[\psi(1+s)^{2}(3-s)(2-s)+2 s^{2}-4 s-2\right]^{2}}-2 D(\alpha) . \\
C S^{\mathrm{FC}}=\frac{(2-s)(1+s)^{2}(a-c)^{2} \psi^{2}}{\left[\psi(1+s)^{2}(2-s)-4 s\right]^{2}}, \\
W^{\mathrm{FC}}=(a-c)^{2} \psi^{2} \frac{(1+2 s)(2-s)(1+s)^{2} \psi-8 s^{2}}{\left[\psi(1+s)^{2}(2-s)-4 s\right]^{2}}-2 D(\alpha) . \\
C S^{\mathrm{PC}}=\frac{(2-s)(3-s)^{2}(1+s)^{2}(a-c)^{2} \psi^{2}}{\left[(1+s)^{2}(3-s)(2-s) \psi+2 s^{2}-4 s-2+2 \alpha\left(s^{2}-4 s+1\right)\right]^{2}} .
\end{gathered}
$$




$$
W^{\mathrm{PC}}=\frac{(a-c)^{2} \psi^{2} \varrho(\psi, s, \alpha)}{\left[(1+s)^{2}(3-s)(2-s) \psi+2 s^{2}-4 s-2+2 \alpha\left(s^{2}-4 s+1\right)\right]^{2}}-2 D(\alpha)
$$

with

$\varrho(\psi, s, \alpha)=(1+2 s)(2-s)(1+s)^{2}(3-s)^{2} \psi-4\left(1+2 s-s^{2}\right)^{2}+\alpha\left(4+16 s-4 s^{4}-64 s^{2}+32 s^{3}\right)$. 